\title{
Importancia del sector industrial para el desarrollo de la economía brasileña
}

\author{
Carmem Aparecida Feijó y Marcos Tostes Lamonica
}

RESUMEN

En el presente artículo, basado en los postulados de Kaldor sobre las fases del desarrollo, se concluye que - a pesar de haberse modernizado gracias al proceso de apertura económica - la estructura industrial brasileña muestra una evolución caracterizada por el aumento de la participación en la producción de bienes de bajo contenido tecnológico. La tendencia a la apreciación del real, al comienzo de la apertura económica, influyó positivamente en la modernización del parque tecnológico brasileño, pero su prolongación en los últimos años —en el marco de una elevada liquidez internacional para los países emergentes- pone en peligro la evolución del sector manufacturero nacional. Esta podría sufrir un retroceso tecnológico, proceso que según el principio de causalidad circular acumulativa afecta negativamente a la capacidad de encadenamiento del sector industrial con los demás sectores de actividad y acentúa la dependencia externa de la economía a largo plazo.

PALABRAS CLAVE

CLASIFICACIÓN JEL

AUTORES
Sector industrial, productos manufacturados, bienes de consumo, bienes de capital, desarrollo económico, producto interno bruto, estadísticas industriales, indicadores económicos, Brasil

O11, O14, L16

Carmem Aparecida Feijó es profesora titular de la Universidad Federal Fluminense e investigadora del Consejo Nacional de Desarrollo Científico y Tecnológico (CNPq). cfeijo@terra.com.br

Marcos Tostes Lamonica es profesor adjunto de la Universidad Federal Fluminense. marcostostes@hotmail.com 


\section{I}

\section{Introducción}

La controversia sobre el papel que desempeña el sector manufacturero en el desarrollo de la economía brasileña se ha intensificado últimamente, debido a la constatación de que la participación del sector en el producto ha venido disminuyendo más o menos en forma sostenida desde los años ochenta y, de manera más acentuada, desde la estabilización económica del primer quinquenio de los años noventa (Marquetti, 2002; Palma, 2005; Barros y Pereira, 2008; Bresser-Pereira, 2008; Nassif, 2008a; Oreiro y Feijó, 2010, entre otros). La controversia se produce sobre todo en torno del efecto que ejerce la valorización del tipo de cambio en el desempeño potencial de la industria.

La tendencia a la apreciación del real se prolongó durante gran parte de la década de 1990 y se vio interrumpida por la modificación del régimen cambiario en enero de 1999. A partir de 2003, junto con la mejora de los términos de intercambio, la moneda brasileña vuelve a mostrar una tendencia a la valorización. Si bien la apreciación cambiaria beneficia al sector productivo porque abarata el costo de las importaciones de insumos y bienes de capital, también desincentiva las exportaciones. La repercusión en la estructura productiva depende de la medida en que esos efectos se traduzcan en un aumento de la productividad que compense la pérdida relativa de competitividad. También se podría decir que el efecto de un cambio valorizado en la estructura productiva solo puede ser positivo si contribuye a una transformación estructural que amplíe la oferta de productos con una elevada elasticidad-ingreso de las exportaciones, y reduzca la dependencia de productos que presenten una alta elasticidad-ingreso de las importaciones. Según la ley de Thirlwall, si así ocurriera, la capacidad de crecimiento a largo plazo se estaría ampliando, es decir, la restricción externa al crecimiento estaría descendiendo.

El propósito de este artículo es analizar la medida en que la disminución del peso relativo del sector manufacturero en el producto interno bruto (PIB) del Brasil refleja un proceso de reestructuración productiva que permitiría al país acercarse a la frontera tecnológica, o un retroceso de la estructura industrial que reduciría el potencial de crecimiento futuro. Según el enfoque tradicional del desarrollo económico, la profundización de la especialización productiva obedece al funcionamiento del mercado, por lo que la apertura económica registrada a partir de los años noventa habría facilitado la modernización de la estructura industrial, a pesar de la preponderancia de los productos de escasa intensidad tecnológica. En cambio, en el enfoque heterodoxo no solo se propugna un modelo de desarrollo manufacturero basado en las industrias de mayor contenido tecnológico, sino que se aboga en favor de que el ritmo de crecimiento de la economía esté determinado por el dinamismo de una industria competitiva en la producción de bienes de alto contenido tecnológico.

El análisis presentado en este artículo se enmarca en los postulados de Kaldor, quien - junto con reconocer la importancia del sector manufacturero como factor de desarrollo económico- demostró que una estructura industrial más sofisticada desde el punto de vista tecnológico presenta encadenamientos intra e intersectoriales más sólidos y complejos, que elevan el potencial de mayor crecimiento. La aplicación de los postulados de Kaldor al caso del Brasil en los años noventa y la primera década del presente siglo, así como estadísticas descriptivas, permiten concluir que pese a la posibilidad de modernización que ofrecía la apertura económica, la modificación de la composición sectorial de la industria revela un proceso de especialización en la producción de bienes de escaso contenido tecnológico. La tendencia a la apreciación de la moneda brasileña, con posterioridad a la estabilización de los precios internos, se identifica como un relevante factor explicativo de la dificultad del país para avanzar en la transformación estructural, en el sentido de adquirir un perfil tecnológico más avanzado. El aporte de este artículo es la demostración de que, en un lapso de dos décadas, la tendencia a la apreciación cambiaria puede haber ejercido una influencia positiva en la fase inicial de estabilización de los precios, pero que su persistencia en el marco de una elevada liquidez internacional pone en peligro la evolución de la industria.

Además de esta breve Introducción, el artículo consta de otras tres secciones. En la segunda sección se describe el marco teórico de Kaldor, donde se analiza el papel especial que desempeña el sector manufaturero en el proceso de desarrollo económico. En la tercera sección se exponen argumentos empíricos para caracterizar los cambios registrados en la estructura industrial brasileña y en la última sección se dan a conocer las consideraciones finales. 


\section{II}

\section{Marco analítico estructuralista de Kaldor}

El interés por comprender el proceso de desarrollo económico de los países menos desarrollados se incorporó a la agenda de investigación de los economistas en los años cuarenta y cincuenta, cuando comenzaba a articularse el pensamiento estructuralista de la Comisión Económica para América Latina y el Caribe (CEPAL). Los avances en el debate teórico convirtieron a la política económica estructuralista en defensora de la industrialización de los países no industrializados, con miras a una mejor inserción de sus economías en la corriente de comercio. En la práctica, la industrialización tardía dio origen en los países de la periferia a una estructura productiva muy heterogénea y relativamente poco diversificada, que se contrapone a la estructura más homogénea y muy diversificada de las economías centrales.

Fuera de presentar estructuras productivas muy heterogéneas en términos de productividad y remuneración de los factores, el proceso de industrialización mediante la sustitución de importaciones en las economías de la periferia las enfrentó a problemas crónicos de la balanza de pagos, antes de la conclusión integral de la industrialización ${ }^{1}$. En realidad, el proceso no se pudo completar debido a la restricción externa al crecimiento. En los trabajos de Kaldor de los años sesenta y setenta se describe la forma que debería adoptar un proceso integral de industrialización.

\section{A. Kaldor y las cuatro fases de desarrollo económico}

A juicio de Kaldor, la madurez de una economía depende de que haya concluido el proceso de desarrollo industrial. Kaldor (1966) distingue cuatro fases de desarrollo en el proceso de industrialización y sostiene que la maduración de una economía "inmadura" se basa en la expansión de la demanda agregada ${ }^{2}$. Desde este punto de vista, la acumulación de capital que se produce en el proceso de industrialización es la variable clave del desarrollo

\footnotetext{
1 Para una evaluación histórica más detallada de este proceso en la región, véase Bértola y Ocampo (2010), entre otros.

2 Una economía inmadura se caracteriza por una gran disponibilidad de mano de obra en los sectores de baja productividad, que puede ser absorbida por sectores de mayor productividad a medida que el proceso de industrialización se vaya desplazando hacia esos sectores. Los países alcanzarían la fase de madurez cuando los niveles de productividad se homogeneizan.
}

económico, porque acelera el cambio tecnológico que beneficia a toda la economía. Los beneficios del cambio se reflejan en la reducción de los costos unitarios y el perfeccionamiento de la calidad de los productos de exportación, que permiten a los productores nacionales competir en los mercados extranjeros.

La aplicación del esquema analítico de las cuatro fases de desarrollo industrial hace posible evaluar el desarrollo económico de acuerdo con los principios de Kaldor. El esquema se basa en el reconocimiento de que el proceso de industrialización de un país puede producirse en forma acumulativa, lo que significa que la producción de bienes de consumo precedería a la producción de bienes de capital, que en ambos casos y en sus etapas iniciales estarían orientadas a la exportación, es decir, a la demanda externa.

En la primera fase de desarrollo surge una industria nacional de producción de bienes de consumo, como se ha observado en el proceso de industrialización de la mayoría de los países, especialmente los de América Latina. En esta etapa se reduciría la dependencia de las importaciones de este tipo de bienes, pero ya en esa fase se inicia la producción nacional de algunas maquinarias y equipos, dado que la expansión de la demanda de bienes de consumo estimularía el aumento de la oferta de algunas maquinarias que la industria nacional ya estaría en condiciones de producir desde el punto de vista de la tecnología. Sin embargo, la mayor parte de los bienes de capital utilizados seguirían siendo importados, sobre todo los que supusieran una tecnología más avanzada, pero no toda la tecnología de última generación sería exportada por los países más desarrollados. Kaldor consideraba que la introducción y producción de bienes de consumo es relativamente rápida y se agota cuando concluye el proceso de sustitución de importaciones de este tipo de bienes.

Para sustentar las tasas aceleradas de crecimiento el proceso de industrialización debería entrar en una segunda fase, en la que el sector productor de bienes de consumo tendría que comenzar a exportar sus excedentes. Esto permitiría sostener la demanda y ampliar la especialización. Argyrous (1996) afirma que en las dos primeras fases se podrían crear las condiciones necesarias para que la economía se especializara en la producción de bienes de capital, que conduce a la 
siguiente fase ${ }^{3}$. En efecto, en algún punto del proceso de desarrollo industrial la dependencia de la tecnología y el capital importados podría frenar el crecimiento de la producción. Supuestamente, en alguna etapa del proceso de industrialización debería reducirse la restricción externa, lo que permitiría superar la dependencia de capital y tecnología foráneos. La tercera fase se iniciaría cuando el país comenzara a tomar medidas para fomentar la sustitución de importaciones de bienes de capital. Kaldor (1970) consideraba que la realización de cuantiosas inversiones en el sector de bienes de capital se reflejaría en un mayor incremento de la productividad y contribuiría a elevar la competitividad.

En la tercera fase también se hace necesario un esfuerzo destinado a desarrollar una tecnología propia, que pueda incorporarse a las maquinarias y los equipos nacionales y consolide la participación del sector de bienes de capital en la estructura productiva nacional. Entre otras cosas, las medidas de desarrollo de la capacidad tecnológica deben conducir a la creación de nuevos productos que posibiliten la expansión de las exportaciones de productos con mayor contenido tecnológico, lo que a su vez compensaría la ampliación de las importaciones derivada del alza de los ingresos y el aumento consecuente de la demanda de origen endógeno. La cuarta fase, con la que concluye el proceso de industrialización, corresponde a la etapa en que el país se convierte en exportador de bienes de capital. En esta fase, el sector productor de bienes de capital habría alcanzado una madurez tecnológica similar a la de los países industrializados. Kaldor (1966) consideraba que en esta última fase el crecimiento económico mostraría una notable expansión, inducida por la demanda interna y externa de bienes de consumo y de capital.

Argyrous (1996) estima que el éxito de las exportaciones de bienes de capital se genera después de un largo período de desarrollo acumulativo generado por la producción en masa de las industrias nacionales que utilizan bienes de capital. Por lo tanto, las políticas económicas que restringen la producción de bienes de capital podrían obstaculizar el círculo virtuoso de crecimiento.

La tesis expuesta en este artículo en relación con la economía brasileña, es que aunque el Brasil ya había desarrollado una matriz industrial bastante compleja en el período comprendido entre fines de la Segunda Guerra Mundial y mediados de los años ochenta, según

\footnotetext{
${ }^{3}$ Kaldor (1966) emplea el término "especialización" para indicar que el sector está en igualdad de condiciones para competir en el mercado internacional, en términos de productividad y dotación tecnológica.
}

la teoría de Kaldor no habría avanzado con la rapidez necesaria, fundamentalmente por no haber completado las últimas fases de desarrollo (véase la sección III.A) ${ }^{4}$. Un claro indicador del carácter inconcluso del proceso es el hecho de que la balanza comercial es estructuralmente deficitaria en lo que respecta a los bienes basados en un uso más intensivo de tecnología, lo que significa que el país es importador neto de bienes de capital (véase la sección III.B). A esto se suma el hecho de que en los últimos años, a partir de 2004, la coyuntura interna y la situación internacional no han favorecido el proceso de industrialización (véase la sección III.C) y, asimismo, han restado dinamismo a la economía brasileña, que es una de las economías emergentes con menor tasa de crecimiento.

La teoría sobre las fases de desarrollo de Kaldor se puede complementar con el análisis de Fajnzylber (2000, pág. 871), según el cual es imprescindible que una economía, incluso una economía industrializada, cuente con un "núcleo endógeno de dinamización tecnológica" para superar la vulnerabilidad externa del crecimiento. Varios autores desarrollistas concuerdan con esta idea. Por ejemplo, Furtado (1984) sostiene que una economía en desarrollo con un proceso incompleto de industrialización debería recurrir a la "creatividad" para impulsar el crecimiento, es decir, a la innovación tecnológica. Furtado (1984, pág. 27) también considera que la falta de creatividad en el Brasil obedecería a que su industrialización tardía tuvo lugar en el marco de un desarrollo imitativo. Por su parte, Fajnzylber (1983, pág. 286) argumenta que no bastaría con el desarrollo del sector productivo de bienes de capital y que se debería crear un "núcleo endógeno de progreso técnico", fortalecido desde el punto de vista tecnológico y articulado con todo el sistema productivo a fin de dotarlo de dinamismo y lograr la excelencia productiva necesaria para penetrar en el mercado internacional y mantenerse en él $1^{5}$.

El desarrollo de este núcleo se relacionaría con la evolución de la economía en sus fases tercera y cuarta. En el contexto de esta trayectoria, el progreso tecnológico se convierte en un factor esencial para el aumento creciente de la productividad y la competitividad de la economía, y asimismo para hacer posible la expansión

\footnotetext{
4 Véase una evaluación de la importante influencia del sector industrial brasileño en la tasa de crecimiento de la industria y de los demás sectores de la economía en Nakabashi, Scatolin y Da Cruz (2010).

5 Fajnzylber (1983) consideraba que la inexistencia de un sector de bienes de capital bien desarrollado, debida al carácter incompleto de la industrialización de América Latina, era una de las causas fundamentales del déficit comercial crónico de sus economías y también les había impedido alcanzar niveles de excelencia productiva.
} 
de las exportaciones basadas en los ingresos generados por la tecnología, lo que a su vez contribuiría a mitigar la restricción externa del crecimiento. Por consiguiente, y concluyendo así el proceso de industrialización, las economías capaces de desarrollar y absorber nuevas tecnologías modifican la estructura sectorial de la industria y difunden los cambios tecnológicos en todo su ámbito (Cimoli y otros, 2005, pág. 12).

La descripción de Kaldor del proceso de industrialización por etapas se relaciona con su tesis sobre el papel que desempeña la industria en el proceso de crecimiento económico, conocido en la literatura como "leyes de Kaldor"6.

\section{B. Las "leyes de Kaldor" y el crecimiento concebido como desarrollo industrial}

El análisis de las fases de desarrollo de Kaldor se complementa con las llamadas "leyes de Kaldor" para explicar la dinámica del crecimiento económico. En los años sesenta y setenta, Kaldor desarrolló un conjunto de propuestas teóricas que se diferencian de la argumentación neoclásica, con el propósito de explicar las diferentes dinámicas de crecimiento de los países, haciendo hincapié en los factores relacionados con la demanda agregada. Luego de formular en los años cincuenta y comienzos de la siguiente década su teoría del crecimiento, centrada en la acumulación de capital y la distribución del ingreso, Kaldor concibió un modelo de crecimiento basado en el principio de causalidad circular acumulativa, en el que se otorga particular importancia a los cambios en la estructura productiva. A su juicio, el nivel de la demanda agregada de los países obedecía a las diferencias existentes entre sus estructuras productivas, por lo que atribuyó una relevante influencia al sector manufacturero en el crecimiento económico, dado que el sector industrial registraría crecientes rendimientos de escala que contribuirían al incremento de la productividad de toda la economía.

Kaldor (1966 y 1970) formuló un conjunto de leyes con el fin de explicar, mediante hechos estilizados, la dinámica de las economías capitalistas y, en particular,

\footnotetext{
6 Kaldor no expuso sus postulados como "leyes" económicas, pero así se las conoce en la historia del pensamiento económico. El propio autor habría contribuido a ello al no haber cuestionado su definición como tales en el debate posterior a su exposición. El hecho de que Kaldor no haya definido explícitamente sus postulados como "leyes" ha dado origen a diferencias de interpretación sobre su número, que varía entre tres (Targetti y Thirwall, 1989) y cuatro (Targetti, 1992). En este caso se ha adoptado la posición de Targetti (1992).
}

las diferencias entre sus tasas de crecimiento $^{7}$. En las leyes de Kaldor se postula lo siguiente:

Primera ley: existe una relación positiva entre el crecimiento y el producto agregado del sector manufacturero, en virtud de la cual cuanto más alta es la tasa de crecimiento de ese sector, mayor es la tasa de aumento del producto agregado. El sector industrial se convierte en el "motor del crecimiento" gracias a su dinamismo y a la difusión de innovaciones. Los encadenamientos internos del sector manufacturero y sus encadenamientos con los demás sectores inducen un incremento de la productividad dentro y fuera de este. Cuando la industria registra rendimientos crecientes, los cambios en el proceso productivo se difunden en forma sostenida y acumulativa.

Segunda ley: existe una relación positiva entre la tasa de crecimiento de la productividad del sector manufacturero y el aumento del respectivo producto, debido a una relación de causalidad en virtud de la cual cuanto más alta es la tasa de crecimiento de este sector, mayor es también la tasa de acrecentamiento de la productividad. Esta ley se conoce como "ley KaldorVerdoorn". Un incremento de la producción inducido por la ampliación de la demanda conduce a la expansión de la productividad de los sectores que presentan economías de escala de carácter dinámico. Esta ley explica por qué las relaciones de intercambio entre el sector manufacturero y los demás sectores de la economía permiten que se cumpla la primera ley.

Tercera ley: cuanto más alta es la tasa de crecimiento de las exportaciones, mayor es el aumento del producto. Según Kaldor, en las fases más avanzadas de desarrollo económico el incremento del producto interno estaría determinado por el agrandamiento de la demanda de exportaciones. Esta idea se basa en el supuesto de que la expansión de la actividad industrial acrecentaría la productividad en el sector manufacturero, lo que elevaría la competitividad de las exportaciones y estimularía su aumento; a su vez, esto conduciría a un incremento del producto general de la economía. Este modelo de desarrollo se traduciría en un proceso acumulativo de crecimiento en función de los crecientes rendimientos del sector manufacturero. La relación de causalidad

\footnotetext{
7 Kaldor no realizó pruebas econométricas con datos de países en desarrollo, pero sus planteamientos despertaron gran interés en varios de sus seguidores, lo que permitió la ampliación de su modelo que también fue puesto a prueba en otros contextos económicos.
} 
acumulativa obedece a la existencia de rendimientos dinámicos y crecientes de escala en el sector industrial, derivados del progreso técnico estimulado por la expansión de la producción. La existencia de economías de escala eleva el nivel de productividad industrial, lo que aporta mayores ingresos a las empresas y, por ende, amplía su capacidad de inversión. Por consiguiente, la expansión del sector manufacturero estimularía un aumento de la productividad y contribuiría a acelerar el cambio tecnológico en toda la economía, fortaleciendo su competitividad en el mercado externo.

Cuarta ley: el crecimiento de la economía a largo plazo no está limitado por la oferta, sino por la demanda, por lo que en una economía abierta la balanza de pagos es el principal factor restrictivo impuesto por la demanda a la expansión del producto. La sostenibilidad del crecimiento económico dependería de la capacidad del país para mantener la competitividad de las exportaciones, que a su vez dependería del aumento de la productividad del sector manufacturero (segunda ley) ${ }^{8}$. Esto significa que la expansión del producto — condicionada en última instancia por la evolución de la productividad y de la capacidad de aprendizaje existente en la economíadebería producirse cuando la balanza de pagos esté en equilibrio. De esto se deduce que las tasas de incremento de la productividad del sector industrial y del PIB están determinadas por la tasa de crecimiento de las exportaciones en relación con la elasticidad-ingreso de la demanda de importaciones (Thirlwall, 1983).

La condición de equilibrio de la balanza de pagos demuestra cómo las exportaciones contribuyen a aminorar la restricción que esta impone a lo largo del tiempo. Si en el proceso de desarrollo el nivel de exportaciones no aumentara en la medida necesaria para cubrir los gastos adicionales por concepto de importaciones, la demanda agregada tendría que contraerse a largo plazo, lo que reduciría el empleo y el producto. Por este motivo, la expansión de las exportaciones es de importancia

\footnotetext{
${ }^{8}$ Las leyes tercera y cuarta están estrechamente relacionadas. Estas dos leyes fueron formuladas por Kaldor (1970) y formalizadas posteriormente por Dixon y Thirlwall (1975) y Thirlwall (1979).
}

estratégica para la sostenibilidad del crecimiento. Sin embargo, según el modelo de Kaldor-Thirlwall, el efecto que ejercen las exportaciones en el crecimiento del producto depende de la estructura productiva de cada país. Si la economía no ha alcanzado un nivel de industrialización que le permita aprovechar los beneficios de la causalidad acumulativa, los encargados de aplicar la política económica deberían realizar cambios estructurales que conduzcan a ese modelo de desarrollo. Tales medidas deberían centrarse en las industrias con rendimientos de escala crecientes, especialmente las productoras de bienes con mayor contenido tecnológico y valor unitario, es decir, las industrias que emplean una tecnología diferenciada y con base científica9 ${ }^{9}$.

En resumen, Kaldor considera que la acumulación de capital incorporado en las tecnologías modernas conduce a concebir un proceso sostenido de transformación industrial y a facilitar cambios significativos en la estructura productiva, que permitan a la economía nivelarse con la de los países con más altos estándares de productividad. Este autor reconoce que la acumulación de capital ejerce un doble efecto en la productividad del trabajo, que aumenta debido a que los trabajadores emplean mejores maquinarias y al proceso de aprendizaje práctico. Por consiguiente, las economías en desarrollo deberían adoptar una política orientada a la acumulación de capital con el propósito de acelerar la industrialización, dado que el desarrollo de un sector industrial avanzado en términos de tecnología es una base fundamental de sustentación del crecimiento a largo plazo.

\footnotetext{
${ }^{9}$ Prebisch (2000) sostiene que las exportaciones pueden contribuir considerablemente a mitigar la restricción externa al crecimiento. Por lo tanto, el modelo Kaldor-Thirlwall y el modelo centro-periferia de Prebisch tienen en común el interés por los posibles efectos de los desequilibrios de la balanza de pagos en lo que respecta al crecimiento a largo plazo. Aunque el primer modelo se basa en las economías desarrolladas y el segundo en las economías en desarrollo, el análisis de la elasticidad-ingreso de la demanda de importaciones y exportaciones y de los efectos que ejerce en la trayectoria de crecimiento de los países considerada en ambos modelos arroja conclusiones convergentes. Cabe mencionar también la vasta literatura schumpeteriana en la que se corroboran los postulados de Kaldor sobre la dinámica de los rendimientos crecientes. Véanse, entre otros, Dosi, Pavitt y Soete (1990); Dosi y Fabiani (1994), y Verspagen (1993).
} 


\section{III}

\section{Estructura industrial del Brasil}

El proceso de aceleración de la industrialización del Brasil se prolongó desde fines de la Segunda Guerra Mundial hasta mediados de los años ochenta, período en que el valor agregado del sector industrial aumentó del 20\% del PIB en 1947 al 36\% del PIB en 1985. A partir de entonces comenzó a descender y en 2010 representaba poco más de un $15 \%$. Desde el punto de vista de la dinámica del crecimiento, se observa una estrecha correlación entre la expansión del sector manufacturero y la del producto (véase el gráfico 1); de hecho, hasta 1980 la tasa de crecimiento del producto industrial superó la del PIB en la mayoría de los años. A partir de la crisis de la deuda externa a comienzos de los años ochenta, y hasta 2010, el aumento del valor agregado de la industria solo rebasó al incremento del PIB en 10 de esos 30 años. Por lo tanto, los años en que el sector manufacturero se expandió en forma más acelerada coinciden con los de mayor alza del PIB. En el gráfico 2 se ilustran las tasas acumuladas de crecimiento desde 1970 y la relación entre la trayectoria de expansión del sector industrial y del conjunto de la economía. A partir de 1980, y junto con la variación del contexto de liquidez internacional, el sector manufacturero deja de encabezar el crecimiento de la economía.

Dado que existe una estrecha correlación entre el crecimiento de la industria y el del PIB, los ciclos de desarrollo industrial coinciden con los ciclos de desarrollo de la economía brasileña. Entre 1950 y 1980 el sector industrial se expandió aceleradamente, pero en ese último año su crecimiento comenzó a desacelerarse. En el período 1981-2008 la trayectoria de crecimiento de la industria se caracterizó por una etapa de elevada inflación entre 1980 y 1994, escasez de liquidez internacional en los años ochenta, crisis cambiarias en la segundad mitad de los años noventa y otros acontecimientos que redujeron el dinamismo del sector. En este contexto destacan la acentuación de la incertidumbre ante la modificación del régimen cambiario en enero de 1999, la crisis energética de 2001, la crisis de confianza provocada por la elección del primer mandatario vinculado a la izquierda en 2002-2003 y la crisis financiera internacional en el último trimestre de 2008. También cabe recordar que en los años noventa se registraron cambios en el manejo de la política de desarrollo, concretamente la apertura económica y las reformas orientadas a la promoción del mercado, que modificaron significativamente el contexto macroeconómico del desarrollo industrial.

Desde la adopción del Plan de Metas en los años cincuenta, el Estado aplicó una política de desarrollo industrial destinada a la sustitución de importaciones. En los años setenta se tomaron nuevas medidas con el propósito de desarrollar un sector industrial que también

GRÁFICO 1

Tasa anual de crecimiento del PIB y del valor agregado del sector manufacturero, 1948-2010

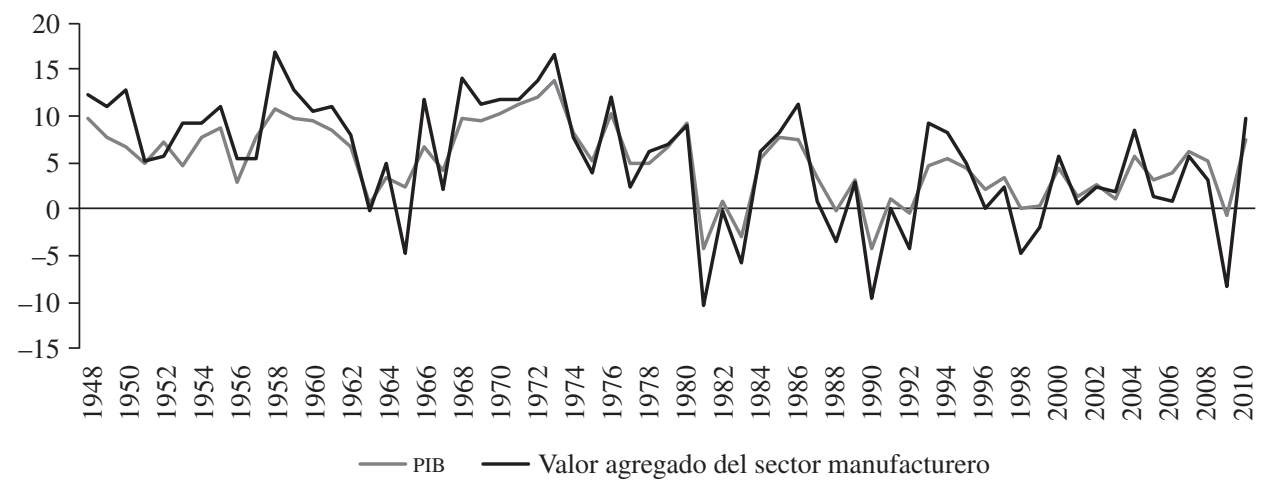

Fuente: Cuentas nacionales y base de datos económicos y financieros (Ipeadata) del Instituto de Investigación Económica Aplicada (IPEA) del Brasil. PIB: producto interno bruto. 


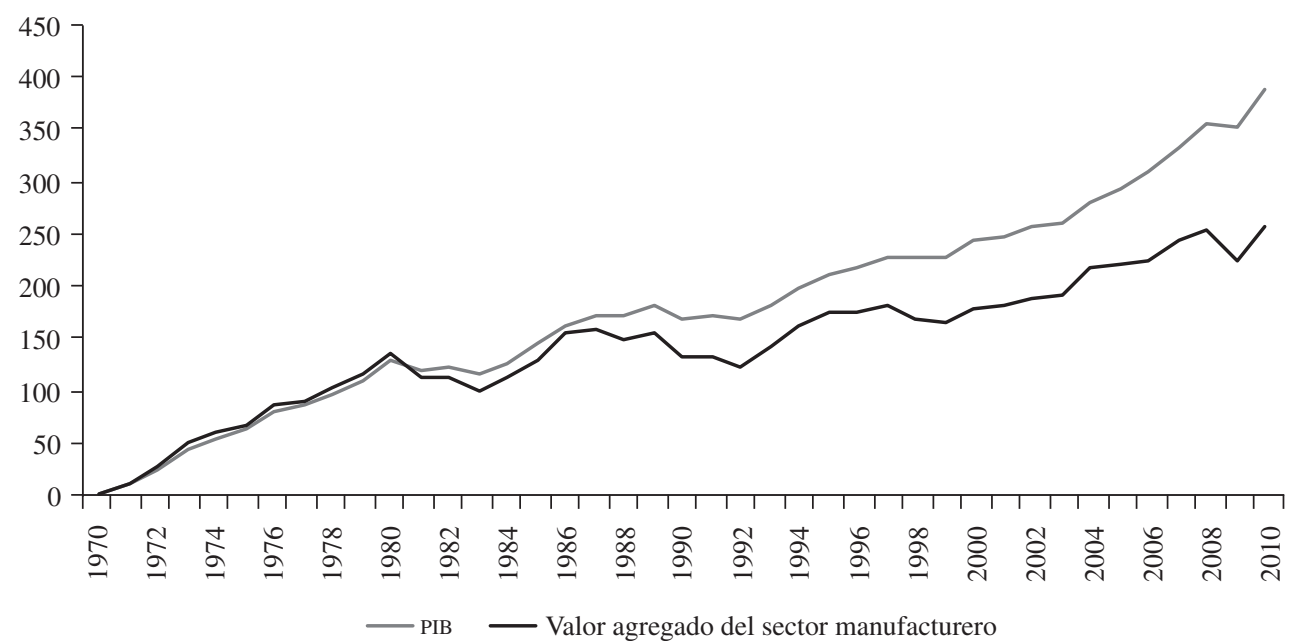

Fuente: Cuentas nacionales y base de datos económicos y financieros (Ipeadata) del Instituto de Investigación Económica Aplicada (IPEA) del Brasil.

a Base $1970=100$.

PIB: producto interno bruto.

produjera bienes y servicios basados en el conocimiento científico y con una base tecnológica diferenciada, pero la crisis de la deuda externa, la aceleración de la inflación y -lo que no es menos importante- el aumento del déficit público interrumpieron este proceso. Una vez controlada la inflación a partir de 1994 y en un contexto macroeconómico de apertura, esos sectores industriales no dispusieron de un ambiente que les permitiera incrementar su participación en el PIB industrial, que se mantuvo invariable. Se podría decir, entonces, que uno de los factores explicativos de la reducción del ritmo de crecimiento de la industria a partir de 1980 podría ser la transformación de la estructura productiva, que supuso una pérdida relativa de dinamismo de la industria productora de bienes más sofisticados desde el punto de vista tecnológico.

En el gráfico 3 se compara la evolución de la expansión del sector productor de bienes de capital, en el que se concentran las industrias basadas en el conocimiento científico y la tecnología diferenciada, con la evolución del sector manufacturero a partir de $1975^{10}$. Según los

\footnotetext{
10 A partir de ese año se dieron a conocer estadísticas mensuales sobre la evolución de los sectores industriales, clasificados por categorías de destino final, recopiladas mediante la Encuesta Industrial Mensual de Producción Física del Instituto Brasileño de Geografía y Estadística (IBGE).
}

postulados de Kaldor, estas industrias son precisamente las que estarían capacitadas para el elevar el ritmo de expansión del PIB, en la medida en que su crecimiento fuera superior al de los demás sectores industriales. Esta propiedad se relaciona con la posición privilegiada que ocupa el sector productor de maquinarias y equipos en la cadena productiva industrial, por tener estrechos encadenamientos hacia atrás y hacia adelante con los demás sectores económicos. Después de una etapa de crecimiento acelerado en los años setenta, este sector mostró un menor dinamismo en la década de 1980 , para luego registrar una expansión menor que la media industrial debido a la apertura económica de los años noventa. A partir de 2003, el crecimiento vuelve a verse impulsado con el comienzo de un nuevo ciclo de inversiones en la economía, interrumpido por la crisis financiera internacional de fines de 2008.

Para profundizar en el análisis del argumento según el cual la composición del sector industrial brasileño no ha mostrado una evolución que conduzca a mitigar la restricción externa del crecimiento, en las subsecciones siguientes se examina su comportamiento a partir de los años setenta de acuerdo con tres elementos de análisis: los cambios registrados debido a la composición del PIB del sector manufacturero y de los sectores de extracción por grado de intensidad tecnológica; los indicadores de la evolución del sector industrial en las distintas fases de 


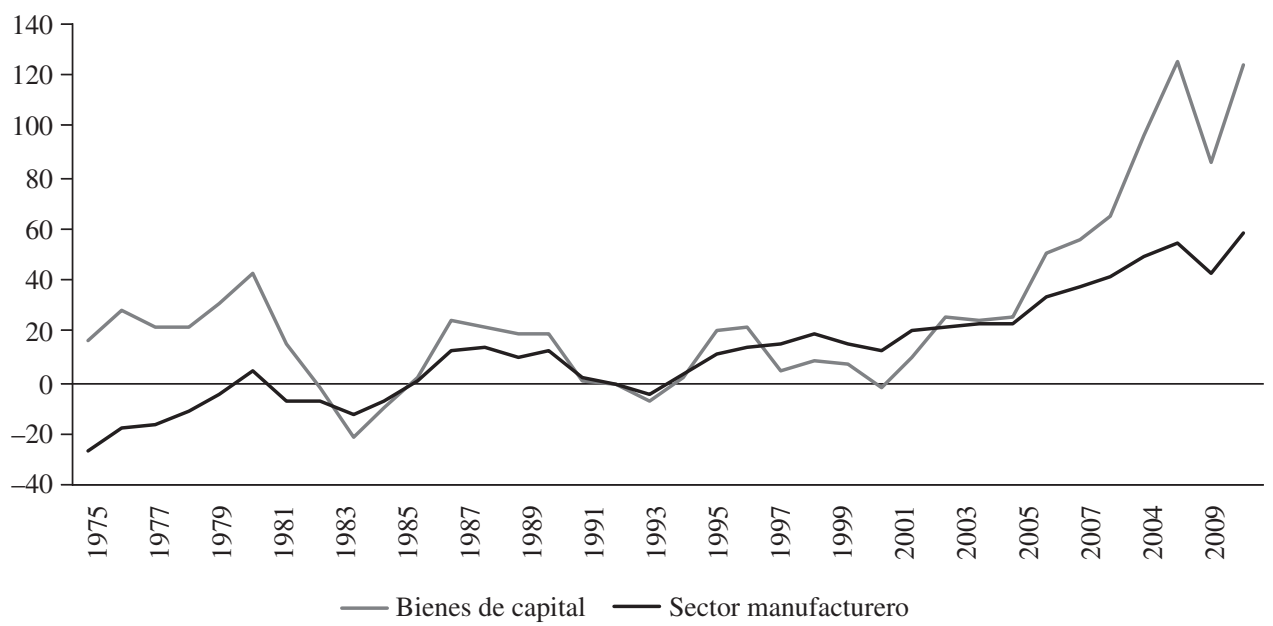

Fuente: Encuesta Industrial Mensual de Producción Física del Instituto Brasileño de Geografía y Estadística (IBGE), series históricas y nueva serie.

a Base $1991=100$

desarrollo identificadas por Kaldor sobre la base de los saldos comerciales de los sectores de bienes de consumo durables y bienes de capital y, por último, un examen de la industria con posterioridad a la apertura económica.

\section{A. La industria brasileña a partir de los años setenta y fases de industrialización}

El proceso de sustitución de importaciones respaldado por las políticas desarrollistas supuestamente habría concluido en los años ochenta, cuando el aporte del sector manufacturero superó el 30\%11. En el cuadro 1 se presenta la evolución de la participación de los sectores de actividad económica, clasificados por tipo de tecnología empleada en los años seleccionados ${ }^{12}$. En dicho cuadro se observa que, ya en 1970, la estructura productiva derivada del proceso de industrialización estaba bastante diferenciada, pero mostraba una escasa representación de los sectores basados en tecnología

\footnotetext{
11 Véanse los análisis de las etapas de desarrollo industrial del Brasil presentados en Bacha y Bonelli (2005) y Lamonica y Feijó (2011), entre otros.

12 En la literatura sobre el tema se ha empleado ampliamente esta clasificación. Véase, entre otros, Nassif (2008a). La selección de los años se realizó en función de la disponibilidad de datos oficiales. En 1970 y 1985 se realizaron censos industriales, que a partir de 1996 fueron sustituidos por la Encuesta Industrial Anual. En Feijó y Carvalho (1999) se presenta un análisis de la disponibilidad de datos estadísticos oficiales sobre el sector industrial del Brasil en la década de 1990.
}

diferenciada y conocimientos científicos. En la década de 1970 se aplicaron dos programas de desarrollo: el primer Plan Nacional de Desarrollo, que abarcó de 1968 a 1973, y el segundo Plan Nacional de Desarrollo, de 1974 a 1979; estos planes permitieron consolidar el proceso de diversificación de la estructura industrial brasileña, pero sin la creación paralela de un núcleo de desarrollo de la innovación tecnológica. La existencia de una industria diferenciada, pero especializada en sectores caracterizados por una base tecnológica media y baja, se prolonga en las décadas siguientes, período en que los cambios más importantes en la estructura productiva se registran en industrias que hacen uso intensivo de recursos naturales y mano de obra y en aquellas intensivas en términos de escala.

También se observa que se incrementó la contribución al valor agregado de los sectores de intensidad tecnológica alta y media-alta, de los que forma parte el sector industrial basado en tecnologías diferenciadas y conocimientos científicos, por el hecho de exigir un mayor aporte de capital y tecnología. En el primer caso, de los sectores basados en tecnologías diferenciadas, la participación en el valor agregado de la industria aumentó un $0,6 \%$ entre 1970 y 2007 y su aporte al valor agregado total fue de alrededor de un $10 \%$, mientras que en el segundo caso, de los sectores basados en conocimientos científicos, fue de apenas un $0,1 \%$, lo que supone un aporte al total de alrededor del $5 \%$ en el mismo período. 
CUADRO 1

\section{Participación porcentual del valor agregado de la industria manufacturera y de extracción de minerales de acuerdo con la intensidad tecnológica, por sectores, 1970, 1985, 1996 y 2007}

Sectores industriales por tipo de tecnología empleada

Participación porcentual

\begin{tabular}{l} 
Basados en recursos naturales \\
\hline Extracción de minerales, petróleo y gas \\
Producción de minerales no metálicos y cemento \\
Metalurgia de minerales no ferrosos \\
Productos de madera \\
Fabricación de papel y pastas para fabricación de papel \\
Elaboración de cueros
\end{tabular}

Elaboración de cueros

Alimentos, bebidas y tabaco

Elaboración de alcoholes y derivados

Fabricación de coque y refinación de petróleo

\begin{tabular}{|c|c|c|c|c|c|}
\hline Intensivos en mano de obra & 15,9 & 15,3 & 13,6 & 10,1 & $-5,8$ \\
\hline Accesorios de viaje y artículos de cuero & 0,1 & 0,1 & 0,1 & 0,1 & 0,0 \\
\hline Textiles & 9,3 & 5,5 & 3,3 & 1,9 & $-7,4$ \\
\hline Vestuario, calzados y artículos tejidos & 3,3 & 4,7 & 4,1 & 3,0 & $-0,3$ \\
\hline Diversos productos & 1,3 & 1,5 & 2,3 & 1,6 & 0,4 \\
\hline Fabricación de productos de metal (excepto maquinarias y equipos) & 1,9 & 3,5 & 3,8 & 3,5 & 1,7 \\
\hline Intensivos en términos de escala & 37,1 & 35,9 & 35,8 & 33,7 & $-3,4$ \\
\hline Metalurgia básica & 10,1 & 9,4 & 4,2 & 6,1 & $-4,0$ \\
\hline Vehículos automotores & 6,3 & 4,7 & 8,1 & 8,5 & 2,3 \\
\hline Equipos de transporte (excepto equipos aeronáuticos) & 1,7 & 0,8 & 0,6 & 1,3 & $-0,3$ \\
\hline Caucho y plástico & 3,8 & 3,8 & 4,1 & 3,3 & $-0,6$ \\
\hline Fabricación de productos y artículos de papel y cartón & 2,4 & 1,2 & 3,1 & 2,8 & 0,3 \\
\hline Fabricación de artículos de perfumería & $\ldots$ & $\ldots$ & $\ldots$ & 1,2 & 1,2 \\
\hline Productos químicos & 6,6 & 13,4 & 9,2 & 6,4 & $-0,2$ \\
\hline Edición, impresión y reproducción de grabaciones & 3,9 & 1,9 & 4,9 & 2,8 & $-1,1$ \\
\hline Productos cerámicos para construcción civil y usos diversos & 1,4 & 0,2 & 1,0 & 0,7 & $-0,6$ \\
\hline Vidrio y productos de vidrio & 0,9 & 0,6 & 0,6 & 0,5 & $-0,4$ \\
\hline Sectores que aplican tecnologías diferenciadas & 9,9 & 10,9 & 13,0 & 10,5 & 0,6 \\
\hline Instrumentos ópticos, cronómetros y relojes & 0,2 & 0,4 & 0,2 & 0,2 & 0,0 \\
\hline Equipos de uso médico y terapéutico & 0,2 & 0,4 & 0,3 & 0,4 & 0,1 \\
\hline Aparatos eléctricos y electrónicos, aparatos y equipos de comunicación & 4,4 & 5,2 & 5,7 & 4,0 & $-0,4$ \\
\hline Máquinarias y equipos & 5,1 & 4,9 & 6,8 & 6,0 & 1,0 \\
\hline Basados en conocimientos científicos & 4,5 & 3,9 & 5,0 & 4,6 & 0,1 \\
\hline Artículos de escritorio y equipos de informática & 0,4 & 0,9 & 0,5 & 0,6 & 0,3 \\
\hline Productos farmacéuticos (y veterinarios) & 3,4 & 1,6 & 3,4 & 2,7 & $-0,7$ \\
\hline Aparatos e instrumentos para mediciones, pruebas y controles & 0,1 & 0,1 & 0,3 & 0,3 & 0,1 \\
\hline Equipos de distribución de energía eléctrica & 0,6 & 0,7 & 0,5 & 0,3 & $-0,3$ \\
\hline Producción y montaje de aeronaves & $\ldots$ & 0,4 & 0,2 & 0,7 & - \\
\hline Maquinarias y aparatos para robotización industrial & $\ldots$ & 0,2 & 0,1 & 0,1 & - \\
\hline Total & 100,0 & 100,0 & 100,0 & 100,0 & - \\
\hline
\end{tabular}

Fuente: Instituto Brasileño de Geografía y Estadística (IBGE), Censo Industrial de 1970 y 1985 y Encuesta Industrial Anual de 1996 y 2007. porcentuales

1970-2007

$\begin{array}{llllll}1970 & 1985 & 1996 & 2007 & & 1970-2007 \\ 32,6 & 34,0 & 32,6 & 41,0 & & 8,4\end{array}$

$2,9 \quad 4,7 \quad 1,6 \quad 4,0 \quad 1,1$

$3,4 \quad 3,0 \quad 2,5 \quad 1,7 \quad-1,7$

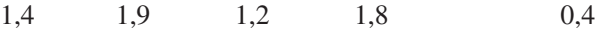

$\begin{array}{lllll}2,4 & 1,4 & 1,1 & 1,3 & -1,1\end{array}$

$\begin{array}{lllll}0,1 & 1,6 & 0,7 & 0,6 & 0,4\end{array}$

$\begin{array}{ccccc}0,5 & 0,5 & 0,3 & 0,2 & -0,3\end{array}$

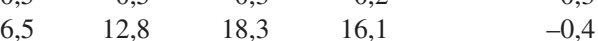

$\begin{array}{rrrrr}2,0 & 3,0 & 1,5 & 0,8 & -1,2\end{array}$

Variación en puntos 
En vista de las ventajas comparativas del Brasil y de sus dimensiones continentales, cabría esperar que el proceso de consolidación del parque industrial se iniciara en los sectores especializados en productos básicos industriales. De hecho, en 1970 la categoría de sectores dedicados a la explotación intensiva de recursos naturales ya contribuía con más del 30\% del valor agregado de la industria, en tanto que el 16,5\% del total del aporte correspondía a las industrias de alimentos, bebidas y tabaco. Esta contribución se redujo a un 12,8\% en 1985, aunque volvió a acrecentarse en 1996 y en 2007, en que registró prácticamente el mismo nivel de contribución que en 1970 (16,1\%), convirtiéndose así en la actividad más importante del sector industrial. A pesar de la relativa estabilidad de la participación porcentual de esta actividad, y tomando en consideración los años de desempeño extremo, la categoría de industrias especializadas en la explotación de recursos naturales amplió su participación en un 8,4\% entre 1970 y 2007. Este incremento obedeció fundamentalmente al aumento de la participación de las actividades de explotación y refinación de petróleo, que representaron un 3,4\% del valor agregado total en 1970, porcentaje que se elevó al $14,5 \%$ en 2007. La creciente importancia de este sector se prolonga desde fines de los años noventa y refleja el comienzo de un cambio relevante en la inserción de la industria brasileña en el comercio mundial.

Entre 1970 y 1985, las industrias que hacen uso intensivo de mano de obra mantuvieron una participación de alrededor del 15\%, que comenzó a descender a partir de este último año, de modo que en $2007 \mathrm{su}$ contribución al valor agregado total era de un $10,1 \%$. El cambio más relevante registrado en esta categoría correspondió a la industria textil, cuya participación ha venido disminuyendo sistemáticamente. La contribución de las industrias productoras de vestuario fluctuó entre un máximo de 4,7\% en 1985 y un 3,0\% en 2007, en tanto que la participación en el valor agregado de la fabricación de productos de metal se consolidó en torno de un 3,0\% a partir de 1985 .

También se ha venido reduciendo la participación de las industrias intensivas en términos de escala, aunque su contribución de aproximadamente el $30 \%$ al valor agregado industrial permite afirmar que, de acuerdo con la secuencia cronológica de Kaldor, la primera y la segunda fase de industrialización del sector industrial brasileño están claramente consolidadas. Los sectores de esta categoría proporcionan los insumos necesarios para la producción de bienes intermedios, tanto de consumo como de capital (metalúrgica básica, caucho y plástico, productos químicos, productos cerámicos y vidrio y productos de vidrio), además de agrupar a los sectores de bienes de consumo y de producción de vehículos, productos de perfumería y edición, impresión y reproducción de grabaciones. Los mayores cambios se han registrado en el sector de metalurgia básica cuya participación disminuyó de 1970 a 2007, y en el sector de vehículos cuya participación aumentó. El sector de productos químicos llegó a representar un 13,4\% del valor agregado del conjunto del sector industrial en 1985 y fue la categoría de mayor peso en ese año; desde entonces, su contribución se mantuvo en torno de un 9\% hasta el año 2000 y en 2007 se redujo a un 6,4\%, porcentaje similar al de 1970 .

Las categorías de sectores basados en tecnologías diferenciadas y conocimientos científicos, que agrupan a los sectores productores de bienes de capital, no muestran mayores variaciones en su participación entre 1970 a 2007. Sin embargo, la media del aporte de estas categorías en el período analizado, que asciende casi a un $15 \%$ del valor agregado del sector industrial, indica que el proceso de industrialización del Brasil ya habría entrado en la tercera fase, en virtud de la ampliación de la diversificación de la estructura productiva y de una significativa participación del sector productor de bienes de capital.

Desde el punto de vista de la secuencia cronológica de las fases de desarrollo industrial, la extensión del proceso de industrialización a los sectores que hacen un uso más intensivo de tecnología se habría visto afectada, incluso en los años ochenta, por la depreciación de la moneda y el consiguiente encarecimiento del costo de los equipos importados, así como por la acentuación de la incertidumbre económica derivada del aumento de la inflación, entre otros factores. La depreciación de la moneda y el aumento de la inflación se debieron a una mayor vulnerabilidad externa, exacerbada por la crisis que afectó a México en 1982. Efectivamente, la crisis de la deuda externa de comienzos de los años ochenta interrumpió el proceso de industrialización, antes de que hubiera transcurrido el tiempo necesario y las inversiones hubieran alcanzado un volumen suficiente para el desarrollo del núcleo endógeno de producción nacional preconizado por Fajnzylber (1983).

Pese a que el proceso de industrialización se vio interrumpido antes de llegar a su término según el modelo de cuatro fases de Kaldor, en la primera mitad de la década de 1980 se registraron elevados superávits comerciales, que coincidieron con la etapa en que la economía brasileña estuvo sujeta a una gran restricción externa. Castro y Souza (2004) atribuyen estos superávits a la maduración de los cambios estructurales generados 
por el segundo Plan Nacional de Desarrollo aplicado en el período 1974-1979.

En resumen, cuando se compara la situación de 1970 con la de 2007 se observa que las variaciones en la estructura productiva fueron bastante circunscritas. El aumento de la participación relativa de los sectores basados en recursos naturales se relaciona con la mayor gravitación adquirida por la industria petrolera, en tanto que la pérdida de importancia relativa de los sectores que hacen uso intensivo de mano de obra se vincula al descenso de la participación de la industria textil. La pérdida relativa de relevancia del segmento intensivo en términos de escala se relaciona con la pérdida de importancia de la industria de metalurgia básica. La participación de las categorías de industrias basadas en tecnologías diferenciadas y conocimientos científicos registró escasas variaciones entre el primer y último año considerados en el cuadro 1 . Todo lo anterior pone de manifiesto la clara tendencia a la especialización del sector industrial brasileño en aquellas actividades que hacen uso intensivo de recursos naturales. Debido a esta propensión, la estructura industrial del Brasil ha mostrado una relativa rigidez en las cuatro últimas décadas. Las variaciones en la participación relativa de los sectores fueron más intensas entre 1985 y 2007, lo que acentuó la concentración de la industria en la producción de bienes que suponen un uso intensivo de recursos naturales. Según el modelo de desarrollo industrial de Kaldor, la industria brasileña no habría llegado a un nivel de madurez en términos de desarrollo industrial.

Como complemento de este último comentario, en el gráfico 4 se examina otro indicador para demostrar que la industria brasileña necesita seguir avanzando para entrar en la fase de madurez. En él se ilustra la evolución del contenido agregado en relación con el valor de producción de las categorías incluidas en el cuadro 1, en tres años: 1985 , cuando se puede suponer que ya había concluido una etapa importante del proceso de sustitución de importaciones; 1996, cuando se puede considerar que ya habían empezado a manifestarse los efectos de la apertura iniciada a fines de los años ochenta en la estructura industrial; y 2007, año que antecede a la crisis financiera internacional ${ }^{13}$. Dado que el coeficiente considerado va en descenso en el conjunto del sector industrial y este fenómeno se acentúa en el período posterior a la apertura económica,

13 El coeficiente valor agregado a valor de producción se calcula dividiendo el valor de procesamiento industrial — que utiliza el IBGE en las encuestas industriales de los últimos años como variable representativa del valor agregado - por el valor bruto de la producción industrial. se supone que podría utilizarse como indicador de que parte de la demanda que anteriormente se registraba en la industria nacional se habría desplazado al exterior. En varios estudios empíricos se destaca la manifestación de este efecto a partir de la década de 1990, que condujo a una profundización del debate sobre la "desindustrialización" del país ${ }^{14}$.

A pesar de lo indicado, en la literatura sobre organización industrial se afirma que, en realidad, este coeficiente mide el grado de verticalización del sector industrial, por lo que su disminución no supondría obligatoriamente un aumento relativo del uso de insumos importados y, en cambio, podría señalar una intensificación de la especialización industrial. En el contexto de este artículo, la duda que se plantea es si el refuerzo de la especialización de la industria brasileña, que de hecho se produjo, se está dando precozmente en vista de que el coeficiente valor agregado-valor de producción empieza a declinar en toda la industria en 1996, es decir, antes de que esta haya llegado a la madurez. Como se observa en gráfico 4, entre los años 1985 y 1996 el coeficiente aumentó de 0,46 a 0,47 en toda la industria y se redujo a 0,43 en 2007. La categoría de sectores industriales que hacen uso intensivo de recursos naturales es la única que presenta un leve incremento del contenido agregado entre 1985 y 2007 (de 0,47 a 0,48). En todas las demás categorías se registra una pérdida de la capacidad de la industria nacional para añadir valor al proceso de transformación productiva, pérdida que es más acentuada en las categorías de sectores que hacen uso intensivo de conocimientos científicos y tecnología diferenciada, y en los sectores intensivos en términos de escala.

\section{B. Balanza comercial de bienes de consumo du- rables y bienes de capital: de la consolidación del sector industrial a la apertura económica de los años noventa}

El análisis de la corriente de comercio internacional también revela que se han producido cambios en la estructura industrial de un país. En lo que respecta a los sectores productores de bienes finales, en el gráfico 5 se ilustra la evolución de los saldos de las balanzas de bienes de consumo durables y bienes de capital en el período comprendido entre 1974 y 2010. La industria

\footnotetext{
14 En relación con este tema, véanse los estudios del Instituto de Estudios para el Desarrollo Industrial (IEDI). Véanse también Feijó, Carvalho y Almeida (2005) y Oreiro y Feijó (2010), entre otros.
} 


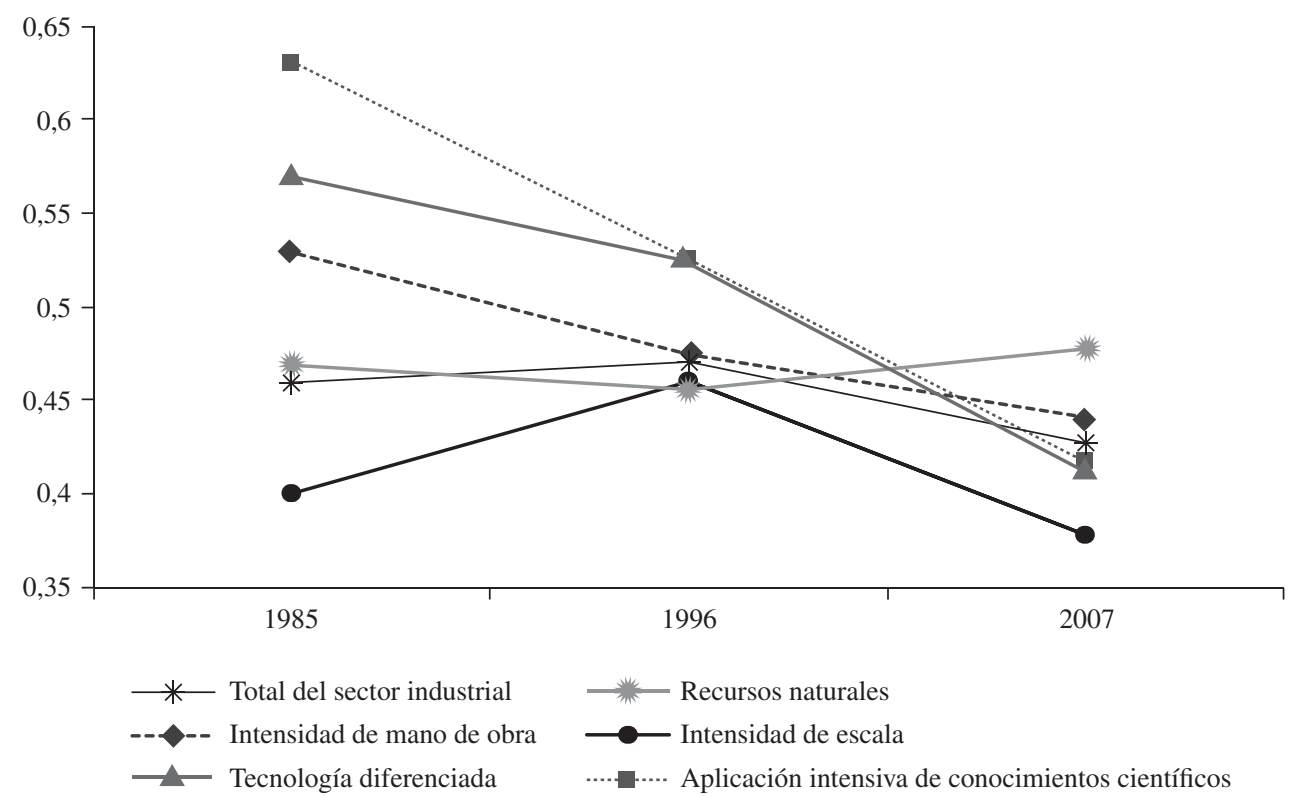

Fuente: Instituto Brasileño de Geografía y Estadística (IBGE), Censo Industrial de 1985 y Encuesta Industrial Anual de 1996 y 2007.

brasileña fue exportadora neta de bienes de consumo durables desde 1977 hasta 1993, etapa en que la economía seguía estando muy protegida por aranceles aduaneros y de otra índole. La falta de apertura de la economía brasileña también se reflejó en un atraso tecnológico de este sector en comparación con otros países de industrialización tardía, especialmente los conocidos como "tigres asiáticos". La apertura comercial de comienzos de los años noventa, unida a la valorización de la moneda, favoreció el aumento del volumen de bienes de consumo importados hasta la modificación del régimen cambiario en 1999. El volumen de exportaciones de bienes durables volvió a incrementarse desde comienzos de la primera década del presente siglo hasta 2005, año en que la valorización cambiaria produjo una nueva contracción que convirtió al país en importador neto de bienes de consumo durables.

La aplicación del segundo Plan Nacional de Desarrollo en los años setenta posibilitó un fortalecimiento del sector productor de bienes de capital, que se concentró en las categorías de actividades basadas en el uso de tecnologías diferenciadas y conocimientos científicos, lo que le permitió avanzar en la tercera fase del proceso de industrialización. Sin embargo, para que el sector pueda madurar es imprescindible el desarrollo tecnológico a nivel nacional. Kaldor considera que el crecimiento económico y la nivelación de una economía en desarrollo con economías más desarrolladas dependen de la maduración de un sector industrial capacitado para crear y producir localmente bienes de consumo para el mercado interno y externo. Los datos estadísticos sobre corrientes de comercio demuestran que la economía brasileña no ha completado la cuarta y última fase de desarrollo industrial y que, en la mayoría de los años a partir de 1974, el saldo de la balanza de bienes de capital fue negativo. En el período comprendido entre 1974 y 1984, caracterizado por la consolidación del sector de bienes de capital gracias a la aplicación del segundo Plan Nacional de Desarrollo, las importaciones superaron a las exportaciones. Desde 1985 hasta 1990 se registraron saldos positivos, con la excepción de 1986 y 1987, años de expansión más acelerada del PIB. A partir de 1991, cuando ya se había iniciado el proceso de apertura económica, las importaciones netas de bienes de capital volvieron a aumentar en forma acelerada, en parte debido a que la intensificación de la competencia interna estimuló la renovación del parque industrial del Brasil, lo que se vio facilitado por la tendencia a la apreciación cambiaria posterior a la estabilización de la inflación. En 2003, y luego del descenso del tipo 
de cambio, el país se convierte en exportador neto. En 2008 se inicia una inversión de la balanza, que en 2010 registra un récord histórico: un saldo negativo de 13.640 millones de dólares.

La comparación de las cifras presentadas en el gráfico 5 con la información contenida en el cuadro 1 permite concluir que el desempeño del sector de bienes de consumo, que agrupa a las actividades de intensidad tecnológica media-alta y alta, sigue siendo insuficiente para dotar a la industria brasileña del dinamismo que necesita para convertirse en el motor del crecimiento económico a largo plazo, es decir, para reducir la restricción externa al crecimiento. El análisis de los saldos comerciales indica que los cambios registrados en la estructura productiva a lo largo de los años no condujeron al aumento efectivo de la participación del sector de bienes de capital, que requiere una mayor capacitación tecnológica. Desde que se inició la apertura económica, la industria instalada mostró un dinamismo suficiente para modernizarse en lo que respecta a los procesos y al acervo (stock) de capital, pero no contó con el impulso necesario para dar un salto en tecnología que le permitiera comenzar a producir bienes con un alto contenido tecnológico y valor agregado. Es indudable que la inexistencia de una política industrial activa en la etapa de apertura económica contribuyó a obstaculizar esta etapa del proceso de industrialización.

En un estudio específico sobre el comportamiento de las importaciones de bienes capital (Nassif, 2008b) se demuestra que este se vio dificultado por los cambios en el entorno macroeconómico. El incremento de las importaciones brasileñas de bienes de capital entre 1989 y 1998 no solo refleja los efectos iniciales de la liberalización
(1990-1994), sino también los derivados de una larga etapa de sobrevaloración cambiaria (1994-1998). En el período 1999-2006 se produjo una desaceleración de las importaciones de maquinarias y equipos a consecuencia de la pronunciada desvalorización cambiaria registrada entre 1999 y 2003 , como también de las bajas tasas de crecimiento de la economía brasileña en el mismo período (Nassif, 2008b, pág. 255) ${ }^{15}$.

Kaldor consideraba que los sectores más dinámicos de la economía, y que por lo tanto podían elevar la calidad de las exportaciones, eran los productores de bienes de intensidad tecnológica alta y media-alta. En el gráfico 6 se presentan los saldos comerciales de los productos industriales clasificados de acuerdo con su intensidad tecnológica a partir de 1989, a objeto de demostrar que la apertura económica y la consecuente modernización del proceso de producción industrial no condujeron a una inversión de la balanza correspondiente a los bienes con contenido tecnológico alto y medio-alto. La persistencia de la apreciación cambiaria, que se inició con la estabilización de los precios en 1994 y —más recientemente- a partir de 2004 con la notable expansión de la demanda interna, contribuyó al aumento del déficit de esta categoría (de bienes de intensidad tecnológica alta y media-alta) industrial (véase el gráfico 7). Por una

\footnotetext{
15 Nassif (2008b) señala que los sectores productores de bombas, compresores y piezas de transmisión; generadores, transmisores y motores eléctricos; estructuras metálicas y calderería pesada, tanques y calderas; y máquinas y herramientas, que tienen una alta participación en la composición de las exportaciones de bienes de capital, han perdido ventaja comparativa (Nassif, 2008b, pág. 258), lo que revela una pérdida de eficiencia de los sectores tradicionales o desarrollados en el Brasil.
}

GRÁFICO 5

Saldo de la balanza comercial de bienes de consumo durables y de capital, 1974-2010 (FOB en millones de dólares)

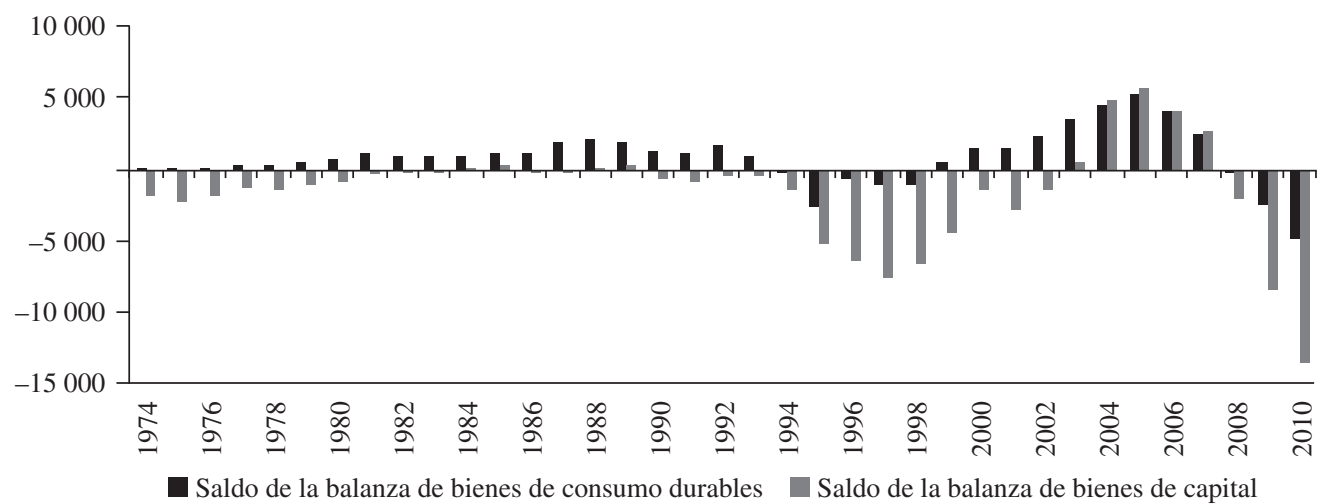

Fuente: elaboración propia sobre la base de datos de la Fundación Centro de Estudios de Comercio Exterior (FUNCEX), y de la base de datos económicos y financieros (Ipeadata) del Instituto de Investigación Económica Aplicada (IPEA) del Brasil. 


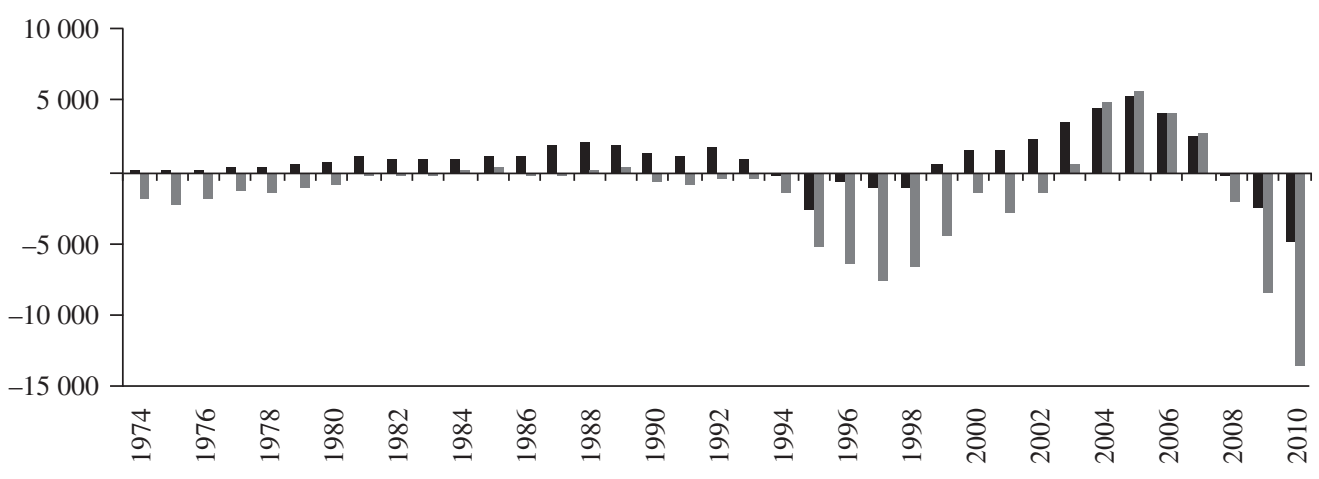

Saldo de la balanza de bienes de consumo durables $\square$ Saldo de la balanza de bienes de capital

Fuente: elaboración propia sobre la base de datos del Instituto de Estudios para el Desarrollo Industrial (IEDI). (Déficit de 34.800 millones de dólares en el sector manufacturero) US\$ bilhões de déficit nos bens da indústria de transformação, Carta $\mathrm{N}^{\circ}$ 451, 2011 [en línea] www.iedi. org.br/cartas

parte, el cambio apreciado redujo el costo de los bienes de capital importados pero, por otra, ha dificultado el desarrollo de su producción en el país. Por consiguiente, el déficit del sector de intensidad tecnológica alta y media-alta refleja el hecho de que el país es importador neto de tecnología. El atraso tecnológico que esto representa para el Brasil indica que, a largo plazo, el país se está especializando en la producción de bienes de baja intensidad tecnológica y productos básicos, en relación con los que aparece como exportador neto. A pesar de que la balanza comercial no ha sido deficitaria en la última década, en términos generales la exportación de productos básicos ha cubierto gran parte del déficit que el sector manufacturero viene acumulando desde 2007 (IEDI, 2011).

En efecto, el incremento de las exportaciones netas de productos básicos, junto con un tipo de cambio valorizado, no sustentaría el crecimiento a largo plazo en vista de la escasa contribución del sector al crecimiento acelerado. A su vez, la prolongación del tipo de cambio - valorizado por un largo período — tiende a producir una reasignación de recursos perjudicial para el desarrollo y la producción nacional de bienes de intensidad tecnológica alta y media-alta. Debido al tipo de cambio valorizado tendencial, el costo de importación de bienes industriales con mayor contenido tecnológico es inferior al costo de los producidos en el país. En ese sentido, el Brasil muestra una orientación opuesta a la propugnada por la teoría de Kaldor y la teoría estructuralista, expuesta en los textos clásicos de Furtado y Fajnzylber, entre otros. Con la excepción de los adelantos técnicos aplicados a la producción de productos básicos, las innovaciones en materia de productos o procesos provienen del exterior, lo que significa que el "núcleo endógeno de progreso técnico" se orientaría al aumento de las ventajas comparativas de la producción y comercialización de productos básicos, y que la elasticidad-ingreso de la demanda de importaciones seguiría siendo superior a la elasticidad-ingreso de las exportaciones.

Por lo tanto, a pesar de que los sectores productivos ya habían consolidado la primera y segunda fase de la industrialización e iniciado la tercera fase, no se dieron las condiciones necesarias para que el Brasil pudiera nivelarse con los países industrializados a partir de la apertura económica. Esa nivelación solo puede producirse cuando la especialización del sector industrial conduce a un incremento del valor agregado de la producción, un aumento del contenido tecnológico y una acentuación del dinamismo en el sentido de ejercer un mayor efecto difusor en otros sectores de la economía. Entre otras cosas, este proceso podría conducir a la reducción de la heterogeneidad estructural y a una mejor distribución funcional del ingreso. La evolución del sector industrial en los últimos años demuestra que se están produciendo cambios significativos que podrían ser determinantes de su transformación.

\section{Proceso industrial reciente y "enfermedad holandesa"}

Un factor importante para el cumplimiento de las "leyes de Kaldor" es el relacionado con el principio de 
causalidad circular acumulativa. De acuerdo con este principio, los rendimientos crecientes que comienza a registrar el sector manufacturero, a partir de una determinada etapa del desarrollo tecnológico de la estructura productiva, acentuarían la competitividad de las exportaciones, lo que a su vez contribuiría al incremento del producto agregado. Con respecto a la interpretación de los cambios estructurales recientes de la industria brasileña cabe destacar que, como las fases de desarrollo han quedado inconclusas, es posible que las ventajas de la causalidad circular acumulativa no se materialicen. Para que se produzca la nivelación con las economías más avanzadas y la causalidad acumulativa opere en forma virtuosa, es necesario que intervengan otras fuerzas además de los incentivos que se ofrecen a través del mercado, como las políticas industriales y tecnológicas, capaces de inducir las transformaciones que requiere la estructura productiva. Asimismo, las políticas que incentivan la sustitución de importaciones de bienes con alto contenido tecnológico son aún más necesarias cuando el tipo de cambio muestra una tendencia sostenida a la apreciación, como ha sucedido en la economía brasileña desde la estabilización de los precios, y más evidentemente aun, después del año 2004.

La apertura económica en un contexto de estabilidad de los precios y valorización cambiaria ejerció una influencia positiva en la estructura industrial ${ }^{16}$, porque estimuló cambios en la asignación de recursos productivos orientados a modernizar los procesos de producción ${ }^{17}$. Sin embargo, la modernización de la estructura productiva tuvo lugar a pesar del nivel relativamente bajo de las inversiones. De hecho, en los años setenta la tasa de inversión de la economía brasileña se mantuvo en torno del $22 \%$, porcentaje que se redujo a cerca de un $17 \%$ entre 1990 y 2010. La apertura económica y financiera de comienzos de los años noventa, unida a las reformas institucionales de fomento del mercado, ofreció un nuevo escenario macroeconómico a las

\footnotetext{
${ }^{16}$ Hay una extensa literatura sobre los efectos de la apertura económica para el sector industrial. Véanse, entre otros, Feijó (2003); Castro (2003), y Ferraz, Kupfer e Iootty (2004).

${ }^{17}$ La productividad industrial se mantuvo estancada desde mediados de los años ochenta y mejoró en el primer quinquenio de la década de 1990 gracias a la apertura comercial. Sin embargo, se produjo un pronunciado descenso del empleo en los sectores industriales, dado que el producto se expandió sin que se registrara una ampliación significativa del acervo de capital. Véanse los análisis de la evolución de la productividad industrial del Brasil presentados en Bonelli (1996); Bacha y Bonelli (2005); Feijó y Carvalho (2002), y Nassif (2008a), entre otros. En Nassif (2005) se analizan las consecuencias que tuvo la apertura comercial en lo que respecta al patrón de comercio exterior del Brasil.
}

decisiones privadas, caracterizado por la estimulación de la dinámica competitiva ${ }^{18}$. La valorización cambiaria, junto con la eliminación de las barreras arancelarias y de otra índole, otorgó competitividad a las importaciones de productos finales, lo que dio origen a un nuevo patrón de competencia con la producción nacional. En este marco se impuso la necesidad de modernizar los procesos productivos e introducir nuevos productos $\mathrm{y}$, a su vez, la valorización cambiaria facilitó también la reducción de los precios de los insumos y bienes de capital, contribuyendo así a la modernización de los procesos de producción. No obstante, las fuerzas del mercado no fueron suficientes para inducir un cambio estructural más profundo, que permitiera a la economía avanzar en el proceso de industrialización de acuerdo con la secuencia postulada por Kaldor.

En los últimos años, lo que explica el cambio estructural orientado a la mayor especialización productiva es la combinación de un tipo de cambio valorizado, especialmente a partir de 2004, con la valorización de los términos de intercambio. Entre 2004 y 2010, el real se valorizó en alrededor del $60 \%$ y los términos de intercambio se valorizaron en aproximadamente un $35 \%$. La prolongación del tipo de cambio valorizado redujo la competitividad de los sectores intensivos en términos de escala y de mano de obra, lo que se tradujo en una pérdida de participación de esos sectores dentro de la estructura productiva. A su vez, la valorización de los términos de intercambio favoreció a los sectores basados en el uso intensivo de recursos naturales. De hecho, la valorización de los productos básicos, incluso en un contexto de tipo de cambio valorizado, influyó positivamente en el crecimiento de la economía, aunque acentuó la tendencia a la especialización de la industria en esos sectores. En efecto, en el cuadro 1 se observa que en el período comprendido entre 1996 y 2007 se produjo un avance de la estructura productiva de los sectores que hacen uso intensivo de recursos naturales, entre otros, de extracción de minerales, refinación de petróleo, y alimentos, bebidas y tabaco, así como de los sectores intensivos en términos de escala, como la metalurgia básica.

En vista de lo anterior, el alza de los términos de intercambio podría estar conduciendo al predominio económico de los sectores de explotación de recursos naturales en detrimento de los demás, lo que contribuiría

\footnotetext{
18 En Erber (2010) se examinan los cambios que se produjeron en el escenario macroeconómico, concretamente el surgimiento de un nuevo consenso sobre el desarrollo.
} 
a la contracción del sector industrial. Este efecto se relaciona con una de las formas que adopta la "enfermedad holandesa": la expansión del sector de productos básicos y el estancamiento relativo del sector de bienes industriales ${ }^{19}$. Por lo tanto, una valorización cambiaria persistente debida al alza de las exportaciones netas, unida a un aumento de la demanda de recursos naturales (productos básicos minerales o agrícolas), puede dar origen a una "desindustrialización" si no se aplican políticas orientadas a contrarrestar los efectos negativos de la apreciación cambiaria para la industria o si las políticas aplicadas con tal objeto no tienen mayores efectos. El mecanismo de transmisión de una desindustrialización provocada por la "enfermedad holandesa" consistiría en un incremento de la rentabilidad de las exportaciones de productos básicos y una reducción de la rentabilidad en los demás sectores. En el caso de la economía brasileña actual, la tendencia a la valorización cambiaria ilustrada en el gráfico 7 disminuiría la competitividad del sector industrial nacional y reforzaría la propensión al estancamiento de los sectores basados en tecnologías

${ }^{19}$ La expresión "enfermedad holandesa" se empleó originalmente para describir la declinación del sector manufacturero de los Países Bajos después del descubrimiento de grandes reservas de gas en el mar del Norte en los años sesenta. A partir de entonces, se suele relacionar el término con la "maldición de los recursos naturales", aunque cabe observar que, en rigor, la "enfermedad holandesa" sería una manifestación de la "maldición de los recursos naturales". diferenciadas y conocimientos científicos, junto con provocar una contracción de los sectores intensivos en uso de mano de obra e intensivos en términos de escala, por el hecho de elevar el costo de producción en divisas de los sectores estancados. La tendencia a la apreciación cambiaria en la primera década del presente siglo se ha prolongado en forma sostenida desde mediados de 2004 y solo se vio interrumpida en el segundo semestre de 2008, debido al agravamiento de la crisis financiera internacional.

Sin embargo, cabe destacar que el proceso de pérdida relativa de gravitación de la industria con respecto al crecimiento a largo plazo no debe atribuirse solo a la reciente coyuntura de valorización de los términos de intercambio. El manejo de la política monetaria, que mantiene un elevado diferencial de tasas de interés atractivo para la entrada de divisas y se expresa en un superávit de las cuentas de capital y financiera superior a las necesidades de financiamiento de la balanza de pagos, es uno de los factores agravantes de la tendencia a la sobrevalorización cambiaria, que influye negativamente en la competitividad del sector industrial en el caso del Brasi120. En el gráfico 8 se ilustra la evolución

${ }^{20}$ Kaldor (1965, págs. 49 y 50) analiza los efectos negativos para el desarrollo de una sobrevaloración cambiaria y se muestra partidario del establecimiento de una meta cambiaria a través de la política económica. En el caso de una apreciación excesiva, se debería establecer

GRÁFICO 7

Tasa real efectiva de cambio, 1990 a 2010

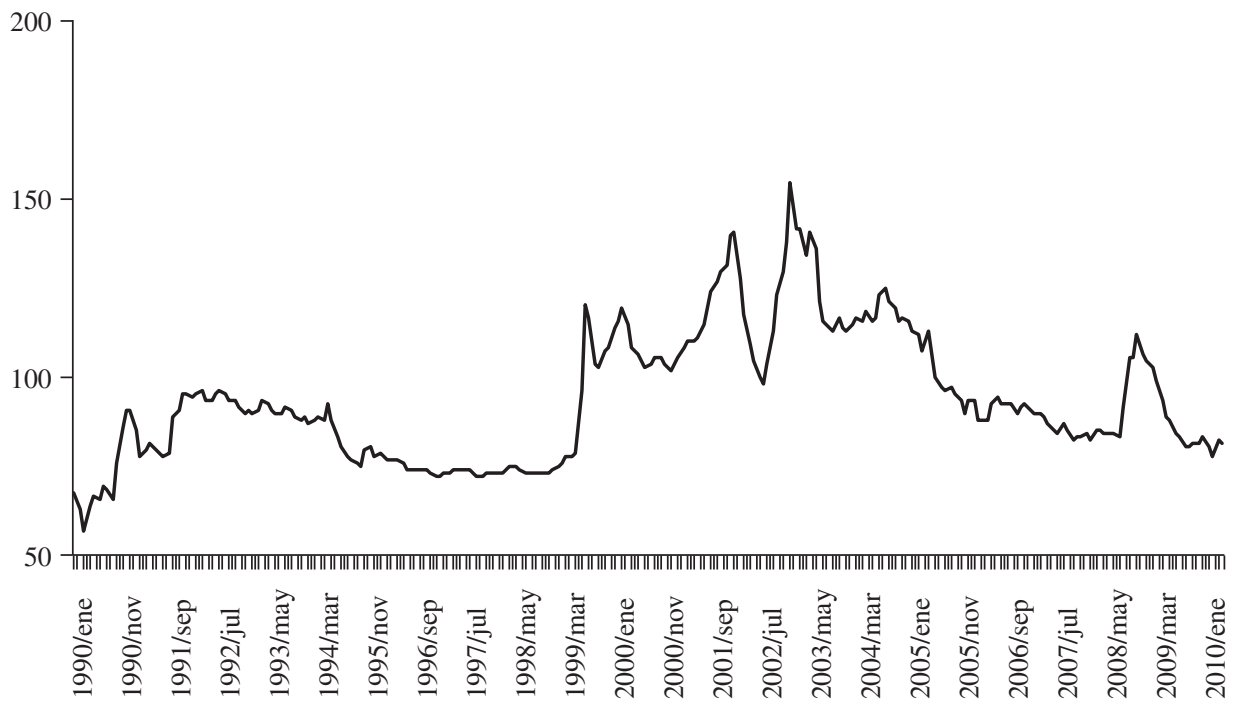

Fuente: Banco Central del Brasil. 


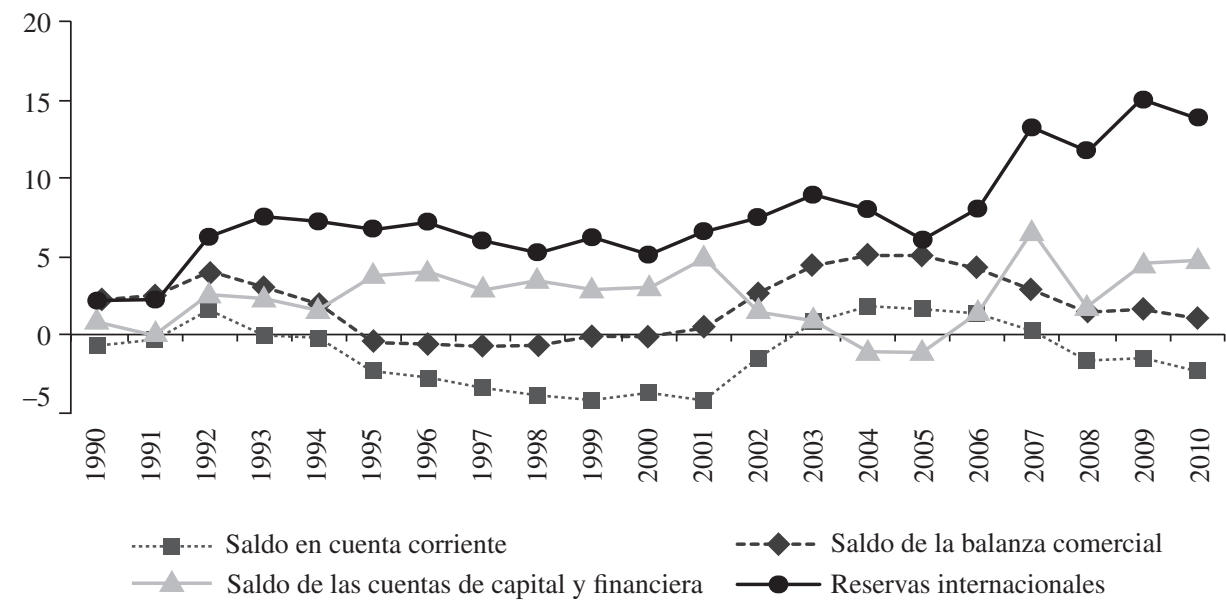

Fuente: Banco Central del Brasil.

PIB: producto interno bruto.

de los saldos de las cuentas de la balanza de pagos como proporción del PIB a partir de 1990. La balanza comercial ha sido positiva desde el año 2000, por lo que a partir de 2003 contribuyó a los saldos positivos de la cuenta corriente. Estos se convirtieron en saldos negativos desde el año 2007 en adelante, pese a que la captación de recursos externos es positiva y abundante, por lo que se ha producido una acumulación excesiva de reservas internacionales que en 2009 representaron el $15 \%$ del PIB. A la presión que ejerce la valorización de los términos de intercambio se ha sumado una política monetaria que, por el hecho mantener el diferencial de tasas de interés a un nivel elevado y atraer recursos externos, amplifica el efecto potencial de la "enfermedad holandesa" y prolonga la sobrevalorización cambiaria.

una meta a mediano y largo plazo. Según Kaldor, “[una devaluación de proporciones adecuadas] presupone la adopción de políticas nacionales destinadas a provocar una marcada deflación paralela al ajuste estructural, además de una serie de reducciones del tipo de cambio, en lugar de un disminución única y definitiva. Es necesario que así sea, porque tanto la conquista de nuevos mercados como la adaptación de la estructura productiva de un país a fin de favorecer a los "bienes internacionales" son procesos prolongados, y el tipo de cambio que pueda ser necesario a la larga para alcanzar la "meta", formulada en términos de participación en el comercio mundial o de una sólida balanza de pagos que pueda mantenerse sin imponer restricciones a las importaciones, representarían un "ajuste excesivo" en caso de adoptarse inicialmente, excesivo en el sentido de que la economía no podría responder a la variación de los precios relativos y, por lo tanto, se vería contrarrestado en gran medida por una inflación".
Se podría decir, entonces, que incluso en un contexto de valorización de los términos de intercambio, la tendencia a la pérdida relativa de participación del sector industrial brasileño no podría definirse como un caso clásico de "enfermedad holandesa", entendida como "maldición de los recursos naturales". Además, el descubrimiento en 2006 de gas natural y petróleo en el estrato presal ${ }^{21}$ no podría considerarse como un posible factor causante de la "enfermedad holandesa", puesto que aún no se ha iniciado su explotación a gran escala. El proceso de relativa desindustrialización de la economía brasileña se caracteriza básicamente por el efecto de valorización de los términos de intercambio de los productos básicos, de los que el país tiene una abundante oferta, y por la tendencia a la apreciación cambiaria sustentada por una política monetaria que mantiene un alto diferencial de tasas de interés en el marco de una elevada liquidez internacional, factor que no es menos relevante que el primero ${ }^{22}$.

\footnotetext{
${ }^{21}$ Capa geológica formada antes de una extensa capa de sal, que puede sobrepasar los dos mil metros de espesor.

${ }^{22}$ Cabe observar que, en general, en el debate sobre la "desindustrialización” brasileña se ha dado más importancia a la valorización del precio de los productos básicos que al papel de la política monetaria. Véase, entre otros, Bresser-Pereira (2008). En Nassif, Feijó e Araújo (2011) se analizan los factores determinantes del cambio registrado en el Brasil con posterioridad a 1999, otorgando primordial importancia al diferencial de tasas de interés. Conviene recordar también que en la literatura poskeynesiana se afirma que en las economías
} 
Según el raciocinio de Kaldor, los efectos positivos del auge de las exportaciones de productos básicos a partir de 2003 tendrían que haberse aprovechado para financiar inversiones destinadas al crecimiento de los sectores más avanzados desde el punto de vista de la tecnología, a fin de retomar el proceso de sustitución de importaciones y permitir que en el futuro el alivio de la restricción externa se produzca sobre bases estables. Lo anterior exigiría inversiones que favorezcan la expansión de los sectores industriales más dinámicos. Por consiguiente, se debería haber revertido el aumento de la capacidad para realizar importaciones, con el propósito de ampliar las posibilidades de absorción del progreso tecnológico mediante la acumulación de capital. Como señaló Salter hace muchos años (Salter, 1966, págs. 153 y 154), se requiere una alta tasa de inversiones para que la estructura productiva cambie aceleradamente y, dependiendo de la demanda, permita un incremento del producto y la productividad de los sectores en los que sea posible un adelanto técnico más rápido.

Pérez (2008) sostiene que los ingresos generados por el sector de productos básicos podrían financiar un "salto hacia el desarrollo"; ello dependería de que se produjera una actualización tecnológica sostenida de las actividades basadas en recursos naturales, que perfeccionara gradualmente el perfil de las exportaciones mediante una continua innovación de los productos y de las actividades y los procesos conexos, y creara bienes de alto valor agregado sobre la base del mercado tradicional de productos básicos. Se podría argumentar que el éxito de una estrategia de esas características depende en gran medida de la coordinación de una política económica de orientación desarrollista, que induzca la creación de un "núcleo endógeno de innovación" a partir de la coyuntura favorable que ofrezca la explotación de recursos naturales en términos de generación de demanda

La situación que se ha dado en el Brasil en los últimos años no coincide con esa descripción. Al respecto, cabe recordar el análisis de Cimoli y otros (2005, págs. 32 y 33), donde se advierte que la existencia de abundantes recursos naturales puede sostener altas tasas de crecimiento durante un cierto tiempo, sin que sea necesario un gran esfuerzo de inversión para la creación de tecnología, pero que — por sí sola— la disponibilidad de recursos naturales es insuficiente para sostener un crecimiento a largo plazo. Esto obedecería a dos motivos:

emergentes las corrientes de capital tienden a ser procíclicas. Véase Resende y Amado (2007). i. el crecimiento basado en factores abundantes no fomenta un cambio estructural, en tanto que el aumento de la productividad en toda la economía reproduce situaciones indeseadas de desigualdad distributiva, deficiente calidad del empleo y heterogeneidad estructural, y

ii. el crecimiento es más vulnerable a los cambios en la economía internacional y al comportamiento de la demanda externa. Lo anterior conduce a estos autores a concluir que la economía es menos vulnerable cuando los ingresos aportados por la producción de tecnología y conocimientos -instrumentos que permiten responder a las variaciones del marco competitivo- son la fuente de crecimiento. Por el contrario, cuando la fuente de ingresos es muy dependiente de un recurso abundante, es mucho más difícil que eso ocurra, debido a la falta de la capacidad tecnológica necesaria para readaptar la economía al nuevo contexto.

Por lo tanto, en el caso del Brasil, según la literatura kaldoriana-estructuralista sobre crecimiento económico, en los últimos 30 años el incremento de la participación en la estructura productiva de los sectores industriales basados en recursos naturales implica un menor ritmo de crecimiento del PIB a largo plazo y una mayor vulnerabilidad ante las crisis externas, sobre todo las que suponen una reducción de la demanda externa. Esto significa que la tasa de crecimiento del PIB a largo plazo, en un marco de equilibrio de la balanza de pagos, será inferior a lo que podría ser, especialmente en comparación con el período de crecimiento acelerado en el contexto de las políticas desarrollistas. Si los sectores industriales basados en tecnologías diferenciadas y conocimientos científicos crecieran por lo menos al mismo ritmo que los sectores basados en recursos naturales, al igual que los sectores agrícola y de servicios, podrían aportar a la economía brasileña tasas de crecimiento a largo plazo superiores tanto a las registradas en la última década, como en el período transcurrido entre fines de la Segunda Guerra Mundial y 1980. Evidentemente, el estímulo al crecimiento acelerado de los sectores industriales basados en tecnologías diferenciadas y conocimientos científicos, así como la ampliación de su participación del PIB industrial, responderían a una política industrial orientada al desarrollo de un núcleo endógeno de tecnología, es decir, de la participación del Estado como fuente de incentivos al desarrollo industrial orientado al aumento del contenido tecnológico de los bienes y servicios producidos en el país. En igual sentido se podría interpretar la afirmación de Ocampo y Vos (2008), según la cual las economías de la periferia deben tomar 
medidas para ampliar el espacio de políticas a fin de promover el crecimiento sostenido.

La actual estructura productiva brasileña y su reflejo en la balanza comercial son frutos del proceso histórico de desarrollo industrial y económico. Según Kaldor (1966 y 1970) y Fajnzylber (1983), si la industria hubiera intensificado su diversificación, la estructura seguiría estando incompleta debido a su participación relativamente baja en el PIB industrial y al déficit comercial recurrente de los sectores que hacen uso intensivo de tecnología. Por otra parte, la explotación en curso de la abundante dotación de recursos naturales del Brasil, en un contexto de valorización de los términos de intercambio, tiene como corolario una valorización cambiaria amplificada por el diferencial de tasas de interés, y el debilitamiento de la industria que empieza por los sectores que hacen uso intensivo de tecnología. Según el enfoque de Kaldor (1966 y 1970) y Fajnzylber (1983), la "enfermedad holandesa" le tendería una trampa al proceso de desarrollo por el hecho de restringir el crecimiento de sectores industriales más intensivos en tecnología. En el caso del Brasil, la trampa podría surgir cuando la explotación de las reservas de petróleo y gas natural del estrato presal llegue a un punto de auge, que elevaría al país a la categoría de gran exportador de esos productos básicos.

\section{IV}

\section{Consideraciones finales}

La profundización de la actual tendencia de la industria brasileña a la especialización en los sectores basados en el uso intensivo de recursos naturales, unida a una contracción relativa de los sectores que hacen uso intensivo de tecnología, especialmente de los sectores productores de bienes de capital, alejaría a la industria brasileña de la maduración postulada por Kaldor. También podría decirse que, de acuerdo con la interpretación de este autor, aún no se habrían agotado todas las posibilidades de desarrollo de la industria brasileña que ofrece el proceso de industrialización.

En términos de las fases de desarrollo establecidas por Kaldor, la estructura productiva brasileña enfrenta el desafío de profundizar las fases 3 y 4 para reducir la restricción externa al crecimiento, sobre todo en lo que respecta a los sectores basados en tecnologías diferenciadas y conocimientos científicos. En consecuencia, el principal obstáculo que dificulta el aprovechamiento del potencial de crecimiento a largo plazo no es el descenso de la participación del producto industrial en la composición del PIB, sino el estancamiento o la reducción de la participación de los sectores que hacen uso muy intensivo de tecnologías en la composición del PIB industrial. Según el mecanismo de causalidad acumulativa de Kaldor, la falta de avances en el proceso de industrialización se traducirá en una inserción menos favorable en las corrientes de comercio, que limitará el ritmo de crecimiento de la economía brasileña a largo plazo, lo que indicaría que esta podría quedar atrapada en un círculo vicioso de crecimiento, en lugar de evolucionar en un círculo virtuoso.

La apertura económica registrada desde los años noventa y la valorización cambiaria contribuyeron a una transformación estructural de la industria. Esa transformación favoreció la modificación del parque industrial, pero también desincentivó las exportaciones y la creación y producción nacional de tecnología, debido al efecto combinado de una tasa de interés real elevada y la valorización del tipo de cambio. Estos serían los primeros síntomas de la "enfermedad holandesa".

La valorización de los términos de intercambio iniciada en 2003 influyó positivamente en el aumento del PIB brasileño a partir de entonces, incluso con un tipo de cambio bajo y tasas de interés real altas, que típicamente desincentivan las exportaciones y las inversiones en bienes con alto contenido tecnológico. Por lo tanto, mientras que variables importantes, como el tipo de cambio y las tasas de interés, impiden un crecimiento sostenido, en la fase actual este se ha logrado en virtud de la valorización de los productos básicos de los que el Brasil es uno de los principales productores mundiales. Cabe preguntarse si este tipo de crecimiento es sostenible a largo plazo. La teoría de Kaldor indicaría que no.

Como señalan Pérez (2008) y Rodrik (2010), a diferencia de lo que ocurre con la especialización, la diversificación de los sectores industriales es esencial para un crecimiento económico sostenido, porque posibilita una mayor variedad de actividades productivas, así como un mejor equilibrio entre los sectores manufactureros en 
términos de participación. En cambio, la combinación perversa que se ha dado en el Brasil entre la valorización de los términos de intercambio, un tipo de cambio valorizado y altas tasas de interés real, ha tenido el efecto inverso de convertir a la economía brasileña en una economía especializada, aunque moderna, y reducir la gama de actividades industriales, es decir, de provocar una concentración sectorial. A juicio de Holland y Porcile (2005, pág. 61), la especialización en sectores de escasa o nula intensidad tecnológica limitaría la capacidad de los países atrasados desde el punto de vista tecnológico, y en particular de los países en desarrollo como el Brasil, para diversificar su estructura productiva en forma competitiva, es decir, sin necesitar protección arancelaria o salarios relativos decrecientes. Por consiguiente, para lograr los objetivos de reducción de la restricción externa y convergencia de los niveles de productividad se requieren inversiones en tecnología que se reflejen en la producción de bienes de consumo y bienes durables destinados a abastecer tanto el mercado interno como el externo.

\section{Bibliografía}

Argyrous, G. (1996), "Cumulative causation and industrial evolution: Kaldor's four stages of industrialization as evolutionary model", Journal of Economic Issues, vol. 30, No 1, Salisbury, Association for Evolutionary Economics, marzo.

Bacha, E.L. y R. Bonelli (2005), "Uma interpretação das causas da desaceleração econômica do Brasil", Revista de economia política, vol. 25, $\mathrm{N}^{\circ} 3$, São Paulo, Centro de Economía Política.

Banco Central del Brasil [en línea] www.bcb.gov.br

Barros, O. y R.R. Pereira (2008), "Desmistificando a tese da desindustrialização: reestruturação da indústria brasileira em uma época de transformações globais", Brasil globalizado, O. Barros y F. Giambiagi (orgs.), Campus, Río de Janeiro.

Bértola, L. y J.A. Ocampo (2010), Desarrollo, vaivenes y desigualdad. Una historia económica de América Latina desde la independencia, Madrid, Secretaría General Iberoamericana.

Bonelli, R. (1996), "Produtividade industrial nos anos 1990: controvérsias e quase-fatos", Economia brasileira em perspectiva, vol. 2, Río de Janeiro, Instituto de Investigación Económica Aplicada (IPEA).

Bresser-Pereira, L.C. (2008), "The Dutch disease and its neutralization: a Ricardian approach", Revista de economia política, vol. 28, $N^{o}$ 1, São Paulo, Centro de Economía Política.

Castro, A.B. (2003), "El segundo catch-up brasileño. Características y limitaciones", Revista de la CEPAL, No 80 (LC/G.2204-P), Santiago de Chile, agosto.

Castro, A.B. y F.P. Souza (2004), A economia brasileira em marcha forçada, Río de Janeiro, Paz e Terra.

Cimoli, M. y otros (2005), "Cambio estructural, heterogeneidad productiva y tecnología en América Latina", Heterogeneidad estructural, asimetrías tecnológicas y crecimiento en América Latina (LC/W.35), M. Cimoli (ed.), Santiago de Chile, Comisión Económica para América Latina y el Caribe (CEPAL).

Dixon, L. y A.P. Thirlwall (1975), "A model of regional growth-rate differences on Kaldorian lines", Oxford Economic Papers, vol. $27, \mathrm{~N}^{\circ} 2$, Oxford, Oxford University Press.

Dosi, G. y S. Fabiani (1994), "Convergence and divergence in the longterm growth of open economies", The Economics of Growth and Technical Change: Technologies, Nations, Agents, G. Silverberg y L. Soete (org.), Aldershot, Edward Elgar.

Dosi, G., K. Pavitt y L. Soete (1990), The Economics of Technical Change and International Trade, Nueva York, New York University Press.

Erber, F.S. (2010), "As convenções de desenvolvimento no Brasil contemporâneo: Um ensaio de economia política", Texto para discussão CEPAL/IPEA, $\mathrm{N}^{\circ} 13$ (LC/BRS/R.230), Brasilia, Oficina de la CEPAL en Brasilia.

Fajnzylber, F. (2000), "Industrialização na América Latina: da "caixa preta' ao "conjunto vazio"”, Cinquenta anos de pensamento na CEPAL, R. Bielschowsky (org.), Río de Janeiro, Record.
(1983), La industrialización trunca de América Latina, México, D.F., Editorial Nueva Imagen/Centro de Economia Transnacional

Feijó, C.A, (2003), "Produtividade do trabalho e emprego: o duplo desafio para os próximos anos, Agenda Brasil: políticas econômicas para o crescimento com estabilidade de preços, J. Sicsu, J.L. Oreiro y L.F. de Paula (orgs.), Barueri, Manole.

Feijó, C.A. y P.G.M. Carvalho (2002), "Uma interpretação sobre a evolução da produtividade industrial no Brasil nos anos noventa e as 'leis' de Kaldor", Nova economia, vol. 12, № 2, Minas Gerais, Universidad Federal de Minas Gerais.

(1999), "O debate sobre a produtividade industrial e as estatísticas oficiais", Economia aplicada, vol. 4, No 4, São Paulo, octubre-diciembre.

Feijó, C.A., P.G.M. Carvalho y J.S.G. Almeida (2005), "Ocorreu uma desindustrialização no Brasil?”, São Paulo, Instituto de Estudios para el Desarrollo Industrial (IEDI) [en línea] www.iedi.org.br/ admin_ori/pdf/20051129_desindustrializacao.pdf

Ferraz, J.C., D. Kupfer y M. Iootty (2004), "Competitividad industrial en Brasil: 10 años después de la liberalización", Revista de la CEPAL, No 82 (LC/G.2220-P), Santiago de Chile, abril.

Furtado, C. (1984), Cultura e desenvolvimento em época de crise, Río de Janeiro, Paz e Terra.

Holland, M. y G. Porcile (2005), "Brecha tecnológica y crecimiento en América Latina", Heterogeneidad estructural, asimetrías tecnológicas y crecimiento en América Latina (LC/W.35), M. Cimoli (ed.), Santiago de Chile, Comisión Económica para América Latina y el Caribe (CEPAL).

IBGE (Instituto Brasileño de Geografía y Estadística), "Censo industrial 1970" [en línea] http://biblioteca.ibge.gov.br/colecao_digital_ publicacoes_multiplo.php?link=censoindustrial\&titulo=Cen so\%20Industrial\%20-\%201960-1985

, "Censo industrial 1985" [en línea] http://biblioteca. ibge.gov.br/colecao_digital_publicacoes_multiplo.php?1 ink $=$ censoindustrial $\&$ titulo $=$ Censo $\% 20$ Industrial $\% 20-\%$ 201960-1985

"Pesquisa Industrial Anual" [en línea] www.ibge.gov.br

"Pesquisa Industrial Mensal de Produção Física" [en línea] www.ibge.gov.br

IEDI (Instituto de Estudios para el Desarrollo Industrial) (2011), "US $\$ 34,8$ bilhões de déficit nos bens da indústria de transformação", Carta IEDI, No 451 [en línea] www.iedi.org.br/cartas

Ipeadata [en línea] www.ipea.gov.br

Kaldor, N. (1970), "The case for regional policies", Scottish Journal of Political Economy, vol. 17, N ${ }^{\circ} 3$, Perth, Scottish Economic Society, noviembre.

(1966), Causes of the Slow Rate of Economic Growth of the United Kingdom, Cambridge, Cambridge University Press. 
(1965), "The relative merits of fixed and floating rates". Publicado también en Further Essays on Applied Economics, Nueva York, Holmes and Meier Publishers, 1978.

Lamonica, M.T. y C.A. Feijó (2011), "Crescimento e industrialização no Brasil: uma interpretação à luz das propostas de Kaldor", Revista de economia política, vol. 31, No 1, São Paulo, Centro de Economía Política.

Marquetti, A.A. (2002), "Progresso técnico, distribuição e crescimento na economia brasileira: 1955-1998", Estudos econômicos, São Paulo, vol. 32, No 1 .

Nakabashi, L., F.D. Scatolin y M.J.V. Da Cruz (2010), "Impactos da mudança estrutural da economia brasileira sobre o seu crescimento", Revista de economia contemporânea, vol. 14, $\mathrm{N}^{\circ}$ 2, Río de Janeiro, Universidad Federal de Río de Janeiro.

Nassif, A. (2008a), "Há evidências de desindustrialização no Brasil?", Revista de economia política, vol. 28, № 1, São Paulo, Centro de Economía Política.

(2008b), "Estructura y competitividad de la industria brasileña de bienes de capital", Revista de la CEPAL, N 96 (LC/G.2396-P), Santiago de Chile, diciembre.

(2005), "Os impactos da liberalização comercial sobre o padrão de comércio exterior brasileiro", Revista de economia política, vol. 25, № 1, São Paulo, Centro de Economía Política.

Nassif, A., C. Feijó y E. Araújo (2011), "The long-term "optimal” real exchange rate and the currency overvaluation trend in open emerging economies: the case of Brazil", Discussion Paper, No 206 (UNCTAD/osG/DP/2011/6), Ginebra, Conferencia de las Naciones Unidas sobre Comercio y Desarrollo (UNCTAD), diciembre.

Ocampo, J.A. y R. Vos (2008), "Policy space and changing paradigm in conducting macroeconomic policies in developing countrie", BIS Papers, № 36, Basilea, Banco de Pagos Internacionales.

Oreiro, J.L. y C.A. Feijó (2010), "Desindustrialização: conceituação, causas, efeitos e o caso brasileiro", Revista de economia política, vol. 30, $\mathrm{N}^{\circ}$ 2, São Paulo, Centro de Economía Política.

Palma, J.G. (2005), "Quatro fontes de desindustrialização e um novo conceito de doença holandesa", documento presentado en la Conferencia "Industrialização, desindustrialização e desenvolvimento" [en línea] www.iedi.org.br

Pérez, C. (2008), "A vision for Latin America: Resource-based strategy for technological dynamism and social inclusion", Globelics Working Paper Series, N WPG0804, Aalborg, Globelics.

Prebisch, R. (2000), "Problemas teóricos e práticos do crescimento econômico", Cinqüenta anos de pensamento na CEPAL, R. Bielschowsky (org.), Río de Janeiro, Record.

Resende, M.F. y A. Amado (2007), "Liquidez internacional e ciclo reflexo: algumas observações para a América Latina”, Revista de economia política, vol. 27, $\mathrm{N}^{\circ} 1$, São Paulo, Centro de Economía Política, enero-marzo.

Rodrik, D. (2010), "Políticas de diversificação econômica", Revista de la CEPAL, número especial en portugués (LC/G.2444-P), Santiago de Chile, mayo.

Salter, W.E.G. (1966), Productivity and Technical Change, Cambridge, Cambridge University Press.

Targetti, F. (1992), Nicholas Kaldor: The Economics and Politics of Capitalism as a Dynamic System, Oxford, Claredon Press.

Targetti, F. y A. Thirlwall (1989), The Essential Kaldor, Londres, Duckworth.

Thirlwall, A.P. (1983), "A plain man's guide to Kaldor's growth laws", Journal of Post Keynesian Economics, vol. 5, No 3, Armonk, M.E. Sharpe, Inc.

(1979), "The balance of payments constraint as an explanation of international growth rates", Banca Nazionale del Lavoro Quarterly Review, Roma, Banca Nazionale del Lavoro, marzo.

Verspagen, B. (1993), Uneven Growth Between Interdependent Economics: A Evolutionary View on Technology Gaps, Trade and Growth, Aldershot, Avebury. 